\title{
Consistent approach to describe and evaluate uncertainty in vibration attenuation using resonant piezoelectric shunting and tuned mass dampers
}

\author{
Benedict Götz ${ }^{1, a}$, Roland Platz ${ }^{2}$ and Tobias Melz ${ }^{1}$ \\ 1 System Reliability and Machine Acoustics SzM, Technische Universität Darmstadt, Magdalenenstrasse 4, 64289 Darmstadt, \\ Germany \\ 2 Fraunhofer Institute for Structural Durability and System Reliability LBF, Bartningstrasse 47, 64289 Darmstadt, Germany
}

Received 2 July 2015, Accepted 29 January 2016

\begin{abstract}
Undesired vibration may occur in lightweight structures due to low damping and excitation. For the purpose of vibration attenuation, tuned mass dampers (TMD) can be an appropriate measure. A similar approach uses resonantly shunted piezoelectric transducers. However, uncertainty in design and application of resonantly shunted piezoelectric transducers and TMD can be caused by insufficient mathematical modeling, geometric and material deviations or deviations in the electrical and mechanical quantities. During operation, uncertainty may result in detuned attenuation systems and loss of attenuation performance. A consistent and general approach to display uncertainty in load carrying systems developed by the authors is applied to describe parametric uncertainty in vibration attenuation with resonantly shunted piezoelectric transducers and TMD. Mathematical models using Hamilton's principle and Ritz formulation are set up for a beam, clamped at both ends with resonantly shunted transducers and TMD to demonstrate the effectiveness of both attenuation systems and investigate the effects of parametric uncertainty. Furthermore, both approaches lead to additional masses, piezoelectric material for shunt damping and compensator mass of TMD, in the systems. It is shown that vibration attenuation with TMD is less sensitive to parametric uncertainty and achieves a higher performance using the same additional mass.
\end{abstract}

Key words: Uncertainty / vibration attenuation / resonant shunt circuit / piezoelectric transducer / tuned mass damper

\section{Introduction}

Structural vibration may occur in several mechanical systems leading to fatigue, reduced durability or undesirable noise. In this context, piezoelectric transducers with a semi-passive inductive resistive electrical network and mechanical tuned mass dampers (TMD) may be an appropriate measure. Both approaches are combined with a host structure and may attenuate its vibration in a limited frequency range, determined by the resonance frequency. Semi-passive vibration attenuation means that no additional energy such as from amplifiers is used for vibration attenuation. However, weak power supply for circuits like a synthetic inductance is necessary. Both attenuation approaches have been subject to research for several decades. A piezoelectric transducer converts mechanical energy into electrical energy. By connecting the electrodes of the transducer to an electrical circuit with

\footnotetext{
${ }^{a}$ Corresponding author: goetz@szm.tu-darmstadt.de
}

resistor and inductance, an electrical oscillation circuit with the inherent capacitance of the transducer is created. Hence, the vibration energy of the host structure can be reduced with the semi-passive approach by transferring it partly to the electrical vibratory system. The passive TMD achieves vibration attenuation in the same way, but no mechanical energy is converted to electrical energy. Only mechanical energy is transferred from the host structure to the TMD. Usually, a TMD is given by tuned mass, stiffness and damper. Both approaches, semipassive and passive, lead to additional masses that affect adversely the construction of lightweight structures. Especially piezoelectric shunt damping is often mentioned in accordance with lightweight design and weight reduction $[1,2]$. Furthermore, replacing a classical passive TMD with a piezoelectric patch transducer connected to a resonant shunt could achieve benefits due to the reduced construction space and a more precise tuning of the electrical shunt components compared to mechanical stiffness and damping. 


\section{Nomenclature}

\begin{tabular}{|c|c|c|}
\hline \multicolumn{3}{|c|}{ Symbols } \\
\hline$\overline{\beta_{r, 33}^{\mathrm{S}}}$ & Relative permittivity at constant strain & - \\
\hline$\eta$ & Mass per length & $\mathrm{kg} \cdot \mathrm{m}^{-1}$ \\
\hline$\lambda_{\mathrm{opt}}$ & Optimal shunt tuning parameter & - \\
\hline$\mu$ & Mass ratio & - \\
\hline$\Omega$ & Excitation angular frequency & $\mathrm{s}^{-1}$ \\
\hline$\omega$ & Angular frequency & $\mathrm{s}^{-1}$ \\
\hline$\omega_{\mathrm{T}}$ & Tuning frequency of TMD & $\mathrm{s}^{-1}$ \\
\hline$\psi$ & Trial function & - \\
\hline$\rho$ & Density & $\mathrm{kg} \cdot \mathrm{m}^{-3}$ \\
\hline$\Theta$ & Electromechanical coupling & N.V $V^{-1}$ \\
\hline$\varphi$ & Phase & $\circ$ \\
\hline$\zeta_{\text {opt }}$ & Optimal TMD damping parameter & - \\
\hline$a$ & Width & $\mathrm{mm}$ \\
\hline$b$ & Damping coefficient & N.s.m ${ }^{-1}$ \\
\hline$C$ & Capacitance & $\mathrm{F}$ \\
\hline$D_{\mathrm{opt}}$ & Optimal shunt damping parameter & - \\
\hline$d_{31}$ & Piezoelectric constant & $\mathrm{m} \cdot \mathrm{V}^{-1}$ \\
\hline$E$ & Young's modulus & N.mm ${ }^{-2}$ \\
\hline$f$ & Frequency & $\mathrm{Hz}$ \\
\hline$F$ & Force & $\mathrm{N}$ \\
\hline$H$ & Transfer function & $\mathrm{mm} \cdot \mathrm{N}^{-1}$ \\
\hline$h$ & Thickness & $\mathrm{mm}$ \\
\hline$I$ & Area moment of inertia & $\mathrm{mm}^{4}$ \\
\hline$k$ & Stiffness & N.m ${ }^{-1}$ \\
\hline$K_{31}$ & Electromechanical coupling coefficient & - \\
\hline$L$ & Electrical inductance & $\mathrm{H}$ \\
\hline$l$ & Length & $\mathrm{mm}$ \\
\hline$m$ & Mass & $\mathrm{kg}$ \\
\hline$q$ & Electrical charge & $\mathrm{Cb}$ \\
\hline$R$ & Electrical resistance & Ohm \\
\hline$r$ & Generalized coordinate & - \\
\hline$v$ & Voltage & $\mathrm{V}$ \\
\hline$w$ & Beam displacement & $\mathrm{mm}$ \\
\hline$z_{\mathrm{T}}$ & Displacement of TMD & $\mathrm{mm}$ \\
\hline $\mathbf{B}_{\mathrm{F}}$ & Forcing vector & - \\
\hline $\mathbf{D}$ & Rayleigh damping matrix & N.s.m ${ }^{-1}$ \\
\hline $\mathbf{K}$ & Stiffness matrix & N.m ${ }^{-1}$ \\
\hline M & Mass matrix & $\mathrm{kg}$ \\
\hline \multicolumn{3}{|c|}{ Subscripts and Superscripts } \\
\hline$\overline{\bar{i}}$ & \multicolumn{2}{|l|}{ Non-deterministic value of a property } \\
\hline$i^{+}$ & \multicolumn{2}{|l|}{ Upper limit of property } \\
\hline $1^{-}$ & \multicolumn{2}{|l|}{ Lower limit of property } \\
\hline$\prod_{0}$ & \multicolumn{2}{|l|}{ Deterministic value of property } \\
\hline $\mathrm{b}$ & \multicolumn{2}{|l|}{ Referring to beam } \\
\hline $\mathrm{F}$ & \multicolumn{2}{|l|}{ Referring to exciting force } \\
\hline $\mathrm{OC}$ & \multicolumn{2}{|l|}{ Open circuit } \\
\hline osc & \multicolumn{2}{|l|}{ Oscillating } \\
\hline $\mathrm{p}$ & \multicolumn{2}{|l|}{ Referring to piezoelectric transducer } \\
\hline $\mathrm{SC}$ & \multicolumn{2}{|l|}{ Short circuit } \\
\hline sh & \multicolumn{2}{|l|}{ Referring to beam with shunted transducers } \\
\hline $\mathrm{T}$ & \multicolumn{2}{|l|}{ Referring to tuned mass damper TMD } \\
\hline TMD & \multicolumn{2}{|c|}{ Referring to beam with tuned mass damper TMD } \\
\hline
\end{tabular}

In general, systems for passive and semi-passive vibration attenuation are designed for a specific problem. However, deviation of the system parameters may lead to mismatch or detuning and, thus, to loss of vibration attenuation performance. Most of the literature examines passive and semi-passive systems with no regard to effects of uncertainty $[1,3-5]$. In references $[6,7]$ electrical quantities of a transducer with resonant shunt are considered to be uncertain. However, no investigations regarding different transducer dimensions and the effect on uncertainty are made. There are many ways, approaches and keywords to describe and evaluate uncertainty in technical context. In this paper three simple categories shall be used to describe and evaluate uncertainty in vibration attenuation: unknown, estimated and stochastic uncertainty. The categories are developed in the German Collaborative Research Center SFB 805 "Control of uncertainty in loadcarrying mechanical systems" (see Sect. 3). In this paper, the categories are used to describe and compare the effects of uncertainty on vibration attenuation of an harmonically excited beam clamped at both ends. For that, piezoelectric transducers with semi-passive inductive resistive shunt, in the following referred to as resonant shunt, and passive TMD are used to attenuate the first transversal eigenmode of the beam. In this paper, the additional mass of both approaches, the resonant shunt and TMD, is used to compare the vibration attenuation performance under uncertainty. Only the mass of the piezoelectric ceramic and the oscillating mass of the TMD are considered as additional masses.

\section{Mathematical models}

This section outlines the derivation of the complex frequency response function of an EULER-BERNOULLI beam with piezoelectric patch transducers and RL-shunt as well as of an beam with TMD. Energy variation with HAMILTON's principle is used to derive and RITZ formulation is used to discretize and solve the equation of motion. Linear time-invariant state space formulations of the beam with resonant shunt and of the beam with TMD are derived and transformed into frequency domain to calculate the frequency response function.

\subsection{Beam with piezoelectric patch transducers}

Figure 1 shows the clamped beam with piezoelectric transducers and shunt design with length $l_{\mathrm{b}}$ of the beam, bending stiffness $E I_{\mathrm{b}}$, density $\rho_{\mathrm{b}}$, thickness $h_{\mathrm{b}}$ and width $a_{\mathrm{b}}$. The length of one piezoelectric transducer is $l_{\mathrm{p}}$, with thickness $h_{\mathrm{p}}$ and width $a_{\mathrm{p}}$. The piezoelectric material properties are represented by the piezoelectric constant $d_{31}$, "3" indicating the direction of the electric field in $z$ direction, and " 1 " indicating the direction of mechanical strain in the piezoelectric transducer in $x$-direction. $\beta_{r, 33}^{\mathrm{S}}$ is the relative permittivity at constant strain. The bending stiffness of one symmetric transducer couple, one on the top and one on the bottom of the beam, is given by 


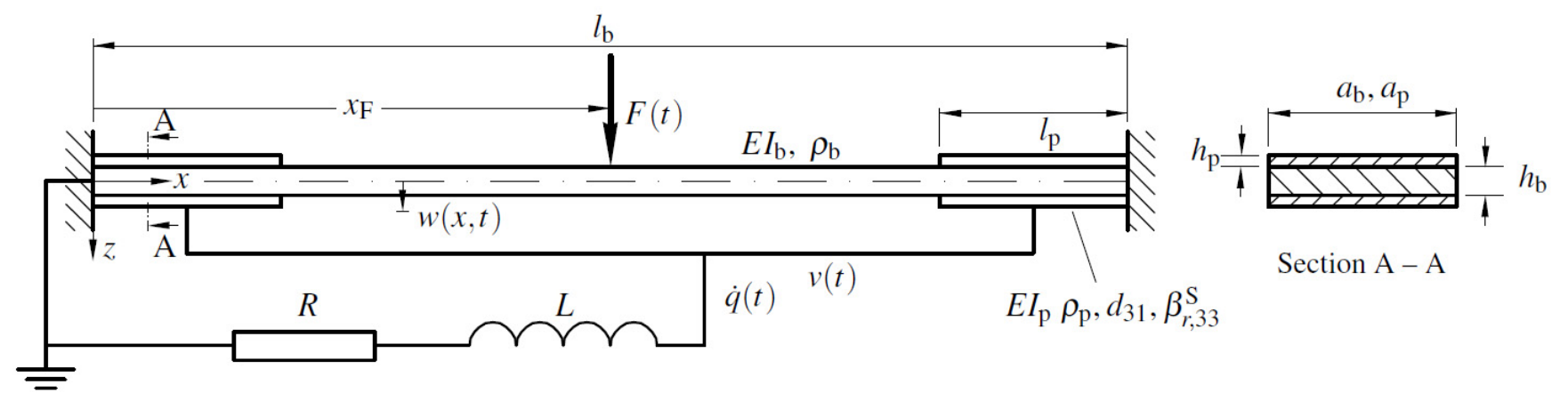

Fig. 1. Model of clamped beam with piezoelectric transducers and shunt design.

$E I_{\mathrm{p}}$. The properties of the resistive inductive shunt are the resistance $R$ and the inductance $L$. For an one dimensional Euler-Bernoulli beam, $w(x, t)$ is the transversal displacement in $z$-direction. The current flowing in the shunt is the first time derivative of the electrical charge $\dot{q}(t)$ and the voltage at the piezoelectric electrodes is $v(t)$. A discrete harmonic force $F(t)=\widehat{F} \cos (\Omega t-\phi)$ with the amplitude $\widehat{F}$, the excitation angular frequency $\Omega$ and phase shift $\phi$ is exciting the beam at location $x_{\mathrm{F}}$.

Four piezoelectric transducers attached to the beam next to the clamps give good vibration attenuation results for the first eigenmode [8] (see Fig. 1).

The equation of motion for a conservative system may be derived using HAMILTON's principle due to energy variation. A generalized form of HAMILTON's principle for an electromechanical system

$$
\int_{t_{1}}^{t_{2}}\left[\delta\left(T-U+W_{\mathrm{el}}\right)+\delta W\right] \mathrm{d} t=0
$$

is given in reference [9] with the kinetic energy $T$, potential energy $U$ and the electrical energy $W_{\text {el }}$ of the beam with piezoelectric patch transducers when excited by the external work $W$. Using RiTz formulation, the lateral displacement $w(x, t)$ of the beam with piezoelectric patch transducers can be approximated by a summation of $K$ trial functions $\psi_{k}(x)$ with $k=1, \ldots, K$ and an associated generalized coordinate $r_{k}(t)[10,11]$ :

$$
w(x, t) \approx \sum_{k=1}^{K} \psi_{k}(x) r_{k}(t)=\Psi^{\top}(x) \mathbf{r}(t)
$$

The trial function $\psi_{k}(x)$ must satisfy the geometric boundary conditions of the beam $w(0, t)=w\left(l_{\mathrm{b}}, t\right)=0$ and $w^{\prime}(0, t)=w^{\prime}\left(l_{\mathrm{b}}, t\right)=0$ and must be differentiable at least to the second space-derivative. In Equation (2), $\boldsymbol{\Psi}(x)$ is the $(K \times 1)$ vector of trial functions and $\mathbf{r}(t)$ is the $(K \times 1)$ vector of the generalized coordinates. Taking into account the mechanical and electrical properties, an actuating equation Equation (3a) and a sensing equation Equation (3b) according to [9] lead to

$$
\begin{aligned}
&\left(\mathbf{M}_{\mathrm{b}}+\mathbf{M}_{\mathrm{p}}\right) \ddot{\mathbf{r}}(t)+\mathbf{D} \dot{\mathbf{r}}(t)+\left(\mathbf{K}_{\mathrm{b}}+\mathbf{K}_{\mathrm{p}}\right) \mathbf{r}(t) \\
&-\boldsymbol{\Theta} v(t)=\mathbf{B}_{\mathrm{F}} F(t)
\end{aligned}
$$

and

$$
\boldsymbol{\Theta}^{\top} \mathbf{r}(t)+C_{\mathrm{p}} v(t)=q(t)
$$

Both equations Equations (3a) and (3b) describe the dynamic behavior of the beam with attached transducers as a coupled electromechanical system.

In Equation (3a), $\dot{\mathbf{r}}(t)$ and $\ddot{\mathbf{r}}(t)$ are the first and the second time derivative of the generalized coordinate $\mathbf{r}(t)$. $\mathbf{M}_{\mathrm{b}}, \mathbf{M}_{\mathrm{p}}, \mathbf{K}_{\mathrm{b}}$ and $\mathbf{K}_{\mathrm{p}}$ are the $(K \times K)$ generalized mass and the $(K \times K)$ stiffness matrices of the beam and the piezoelectric patch transducers. $\mathbf{D}$ is the $(K \times K)$ RAYLEIGH damping matrix

$$
\mathbf{D}=\delta_{1}\left(\mathbf{M}_{\mathrm{b}}+\mathbf{M}_{\mathrm{p}}\right)+\delta_{2}\left(\mathbf{K}_{\mathrm{b}}+\mathbf{K}_{\mathrm{p}}\right)
$$

of the beam with coupled piezoelectric patch transducers assuming proportional damping. The factors $\delta_{1}$ and $\delta_{2}$ are chosen to obtain the assumed damping of $0.5 \%$ for the first two eigenmodes.

The electrical part in Equation (3a) is represented by the electrical voltage $v(t)$ at the transducers electrodes and the $(K \times 1)$ electromechanical coupling vector $\boldsymbol{\Theta}$. The vector elements $\Theta_{k}$ with $k=1, \ldots, K$ of the coupling vector are

$$
\Theta_{k}=\int_{0}^{l_{\mathrm{b}}} 2 E_{\mathrm{p}} d_{31} a_{\mathrm{p}} \frac{h_{\mathrm{b}}+h_{\mathrm{p}}}{2} \psi_{k}^{\prime \prime}(x) \Delta H \mathrm{~d} x
$$

with

$\Delta H=H(x)-H\left(x-l_{\mathrm{p}}\right)+H\left(x-l_{\mathrm{b}}+l_{\mathrm{p}}\right)-H\left(x-l_{\mathrm{b}}\right)$.

$\Delta H$ is the HEAVISIDE step function. The energy converted by the transducer is considered to be proportional to its strain in $x$-direction due to bending only. For an EulerBernoulli beam, the bending strain $\varepsilon_{x}$ is

$$
\varepsilon_{x}(x)=-z w(x)^{\prime \prime} .
$$

The elements of the $(K \times K)$ beam and piezoelectric patch mass matrices are

$$
\begin{aligned}
M_{\mathrm{b}, k, l} & =\int_{0}^{l_{\mathrm{b}}} \eta_{\mathrm{b}} \psi_{k}(x) \psi_{l}(x) \mathrm{d} x \\
\text { and } M_{\mathrm{p}, k, l} & =\int_{0}^{l_{\mathrm{b}}} \eta_{\mathrm{p}} \psi_{k}(x) \psi_{l}(x) \Delta H \mathrm{~d} x
\end{aligned}
$$


with $k=1, \ldots, K$ and $l=1, \ldots, L$ for $K=L$, the masses per length of the beam $\eta_{\mathrm{b}}=\rho_{\mathrm{b}} h_{\mathrm{b}} a_{\mathrm{b}}$ and the transducer patch couple $\eta_{\mathrm{p}}=2 \rho_{\mathrm{p}} h_{\mathrm{p}} a_{\mathrm{p}} . \mathbf{B}_{\mathrm{F}}$ is the $(K \times 1)$ forcing vector

$$
\mathbf{B}_{\mathrm{F}}=\left[\psi_{k}\left(x_{\mathrm{F}}\right), \ldots, \psi_{K}\left(x_{\mathrm{F}}\right)\right]^{\top} .
$$

The elements of the $(K \times K)$ beam stiffness matrix are

$$
K_{\mathrm{b}, k, l}=\int_{0}^{l_{\mathrm{b}}} E I_{\mathrm{b}} \psi_{k}^{\prime \prime}(x) \psi_{l}^{\prime \prime}(x) \mathrm{d} x
$$

The elements of the $(K \times K)$ piezoelectric patch stiffness matrix are

$$
K_{\mathrm{p}, k, l}=\int_{0}^{l_{\mathrm{b}}} E I_{\mathrm{p}} \psi_{k}^{\prime \prime}(x) \psi_{l}^{\prime \prime}(x) \Delta H \mathrm{~d} x
$$

with the bending stiffness

$$
E I_{\mathrm{p}}=2 E_{\mathrm{p}}\left[I_{\mathrm{p}}^{*}+\left(\frac{h_{\mathrm{b}}}{2}+\frac{h_{\mathrm{p}}}{2}\right)^{2} h_{\mathrm{p}} a_{\mathrm{p}}\right]
$$

of one symmetric transducer couple. In Equation (11) $I_{\mathrm{p}}^{*}$ is the area moment of inertia of one rectangular patch transducer related to its center of area.

In Equation (3b), the capacitance of the piezoelectric patch transducers $C_{\mathrm{p}}$ in parallel is given by

$$
C_{\mathrm{p}}=4 \frac{a_{\mathrm{p}} l_{\mathrm{p}} \beta_{0} \beta_{\mathrm{r}, 33}^{\mathrm{S}}}{h_{\mathrm{p}}}
$$

with the vacuum permittivity $\beta_{0}$.

\subsection{Beam with piezoelectric transducers and RL shunt}

An inductive resistive shunt is connected to the beam with piezoelectric patch transducers. Figure 1 shows the shunt connected to the piezoelectric patch transducers. From the second Kirchhoff's law, the voltage from $R$ and $L$ is obtained

$$
v(t)=-L \ddot{q}(t)-R \dot{q}(t) .
$$

Substituting the voltage $v(t)$ in Equations (3a) and (13) by Equation (3b), the equations of motion of the beam with piezoelectric patch transducers and RL-shunt become

$$
\mathbf{M} \ddot{\mathbf{r}}(t)+\mathbf{D} \dot{\mathbf{r}}(t)+\mathbf{K}_{\mathrm{OC}} \mathbf{r}(t)-C_{\mathrm{p}}^{-1} \boldsymbol{\Theta} q(t)=\mathbf{B}_{\mathrm{F}} F(t)
$$

with $\quad \mathbf{K}_{\mathrm{OC}}=\mathbf{K}_{\mathrm{b}}+\mathbf{K}_{\mathrm{p}}+C_{\mathrm{p}}^{-1} \boldsymbol{\Theta} \boldsymbol{\Theta}^{\top}, \mathbf{M}=\mathbf{M}_{\mathrm{b}}+\mathbf{M}_{\mathrm{p}}$

and $L \ddot{q}(t)+R \dot{q}(t)+C_{\mathrm{p}}^{-1} q(t)-C_{\mathrm{p}}^{-1} \boldsymbol{\Theta}^{\top} \mathbf{r}(t)=0$

Equation (14a) describes the beam with coupled piezoelectric patch transducers and charge driven electrodes and Equation (14b) describes the resonantly shunted transducers. $\mathbf{K}_{\text {OC }}$ is the open circuit stiffness with the piezoelectric electrodes open circuited.

\subsubsection{State space model}

With the equation of motion of the coupled electromechanical system Equations (3a) and (3b), a state space model will be introduced. The state space model is transferred into frequency domain to calculate the frequency response function of the beam with patch transducers and with resonant shunt. Therefore, Equations (14a) and (14b) are transferred into first order differential equations to obtain a linear time-invariant state space model formulation. The complete model of the shunted (sh) electromechanical system according to [9] can be written as

$$
\begin{aligned}
\dot{\mathbf{x}}_{\mathrm{sh}} & =\mathbf{A}_{\mathrm{sh}} \mathbf{x}_{\mathrm{sh}}+\mathbf{B}_{\mathrm{sh}} u_{\mathrm{sh}} \\
y_{\mathrm{sh}} & =\mathbf{C}_{\mathrm{sh}} \mathbf{x}_{\mathrm{sh}}+D_{\mathrm{sh}} u_{\mathrm{sh}}
\end{aligned}
$$

with the $[(2 K+2) \times(2 K+2)]$ system matrix

$$
\mathbf{A}_{\mathrm{sh}}=\left[\begin{array}{cccc}
\mathbf{0}^{K \times K} & \mathbf{I}^{K \times K} & \mathbf{0}^{K \times 1} & \mathbf{0}^{K \times 1} \\
-\mathbf{M}^{-1} \mathbf{K}_{\mathrm{OC}} & -\mathbf{M}^{-1} \mathbf{D} & -\mathbf{M}^{-1} \boldsymbol{\Theta} C_{\mathrm{p}}^{-1} & \mathbf{0}^{K \times 1} \\
\mathbf{0}^{1 \times K} & \mathbf{0}^{1 \times K} & 0 & 1 \\
-\mathbf{\Theta}^{\top}\left(C_{\mathrm{p}} L\right)^{-1} & \mathbf{0}^{1 \times K} & -\left(C_{\mathrm{p}} L\right)^{-1} & -R L^{-1}
\end{array}\right]
$$

and the $[(2 K+2) \times 1]$ input matrix

$$
\mathbf{B}_{\mathrm{sh}}=\left[\begin{array}{c}
\mathbf{0}^{K \times 1} \\
\mathbf{M}^{-1} \mathbf{B}_{\mathrm{F}} \\
0 \\
0
\end{array}\right]
$$

$\mathbf{C}_{\text {sh }}$ is the $[1 \times(2 K+2)]$ output vector and $D_{\text {sh }}$ the feedthrough constant:

$$
\mathbf{C}_{\mathrm{sh}}=\left[\begin{array}{llll}
\Psi & \left(x_{\mathrm{F}}\right)^{\top} \mathbf{0}^{1 \times K} & 0 & 0
\end{array}\right], \quad D_{\mathrm{sh}}=0
$$

All state variables are contained in the $[(2 K+2) \times 1]$ state vector $\mathbf{x}_{\mathrm{sh}}$. The input $u_{\mathrm{sh}}$ is the force $F(t)$ and the output $y_{\mathrm{sh}}$ is the beam displacement at $w\left(x_{\mathrm{F}}, t\right)$.

$$
\mathbf{x}_{\mathrm{sh}}=\left[\begin{array}{c}
\mathbf{r}(t) \\
\dot{\mathbf{r}}(t) \\
q(t) \\
\dot{q}(t)
\end{array}\right], \quad u_{\mathrm{sh}}=F(t), \quad y_{\mathrm{sh}}=w\left(x_{\mathrm{F}}, t\right)
$$

To obtain the displacement $w\left(x_{\mathrm{F}}, t\right)$, a transformation from generalized coordinates $r(t)$ to physical coordinates $x(t)$ is performed with the vector of trial functions $\boldsymbol{\Psi}\left(x_{\mathrm{F}}\right)$. Using the particular integral approach the complex transfer function of the beam with patch transducers and with resonant shunt for the beam displacement amplitude $\hat{w}\left(x_{\mathrm{F}}=l_{\mathrm{b}} / 2\right)$ in frequency domain results in

$$
\underline{H}_{\mathrm{sh}}(\Omega)=\frac{\widehat{w}\left(x_{\mathrm{F}}, \Omega\right)}{\widehat{F}}=\mathbf{C}_{\mathrm{sh}}\left(j \Omega \mathbf{I}-\mathbf{A}_{\mathrm{sh}}\right)^{-1} \mathbf{B}_{\mathrm{sh}}+D_{\mathrm{sh}}
$$


with its amplitude and phase response $\left|\underline{H}_{\mathrm{sh}}(\Omega)\right|$ and $\varphi_{\mathrm{sh}}(\Omega)=\arg \left\{\underline{H}_{\mathrm{sh}}(\Omega)\right\}$. With the excitation angular frequency $\Omega$ and the phase shift $\phi$

$$
\begin{aligned}
& \underline{F}(t)=\widehat{F} e^{j(\Omega t-\phi)}, \underline{q}(t)=\widehat{q} e^{j(\Omega t-\phi)} \\
& \text { and } \underline{\mathbf{r}}(t)=\widehat{\mathbf{r}} e^{j(\Omega t-\phi) .}
\end{aligned}
$$

In Equation (20), the phase shift $\phi$ is assumed to be zero. Although $|\underline{H}(\Omega)|$ and $\varphi(\Omega)$ are functions of $\Omega$, in all following figures the amplitude and phase response are plotted as functions of frequency $f$ in $\mathrm{Hz}$ using the conversion $\Omega=2 \pi f$. The amplitude responses are normalized to the static compliance of the beam.

\subsubsection{Optimal tuning parameters}

To attenuate the resonance amplitude of the vibrating host structure, the resonant shunt needs to be tuned according to the first resonance angular eigenfrequency $\omega_{\mathrm{b}}$ of the host structure with piezoelectric patch transducers. Therefore, the optimal value for the inductance $L$ will be calculated. To achieve a maximum broad band damping, the optimal value for the resistance $R$ will be obtained. The optimal values for $L$ and $R$ may be chosen according to [12]. This approach uses the transfer function criterion and minimizes the amplitude response in the attenuated frequency range. The optimal inductance $L_{\text {opt }}$ and the optimal resistance $R_{\mathrm{opt}}$ are

$$
L_{\mathrm{opt}}=\frac{\lambda_{\mathrm{opt}}}{C_{\mathrm{p}}\left(\omega_{\mathrm{OC}}\right)^{2}} \quad \text { with } \quad \lambda_{\mathrm{opt}}=\frac{1}{1+K_{31}^{2}}
$$

and

$$
R_{\mathrm{opt}}=\frac{2 D_{\mathrm{opt}}}{C_{\mathrm{p}} \omega_{\mathrm{OC}}} \quad \text { with } \quad D_{\mathrm{opt}}=\sqrt{\frac{1}{2 / K_{31}^{2}+4+2 K_{31}^{2}}}
$$

In Equation (22), $\lambda_{\mathrm{opt}}$ is the tuning parameter and $\omega_{\mathrm{OC}}$ is the first open circuit angular eigenfrequency. The actual angular eigenfrequency of the tuned electrical shunt is $\omega_{\mathrm{el}}=1 / \sqrt{C_{\mathrm{p}} L}$. In Equation (23), $D_{\text {opt }}$ is the optimal damping. In Equations (22) and (23), $K_{31}$ is the generalized electromechanical coupling coefficient. It characterizes the energy exchanged between the mechanical and the electrical domains. The coupling coefficient $K_{31}$ is influenced by the piezoelectric material properties, patch transducer dimensions and location on the beam. A high coupling coefficient will lead to high vibration attenuation. $K_{31}$ for the first angular eigenfrequency may be obtained from the first open circuit angular eigenfrequency $\omega_{\mathrm{OC}}$ and the first short circuit angular eigenfrequency $\omega_{\mathrm{SC}}$ according to

$$
K_{31}=\sqrt{\frac{\left(\omega_{\mathrm{OC}}\right)^{2}-\left(\omega_{\mathrm{SC}}\right)^{2}}{\left(\omega_{\mathrm{SC}}\right)^{2}}}
$$

Assuming only minor damping, damped angular eigenfrequencies may be neglected. Thus the short circuit and the open circuit angular eigenfrequencies are obtained solving the eigenvalue problem of the undamped system

$$
\begin{aligned}
& \operatorname{det}\left[\left(\mathbf{K}_{\mathrm{b}}+\mathbf{K}_{\mathrm{p}}\right)-\left(\omega_{\mathrm{SC}}\right)^{2} \mathbf{M}\right]=0 \text { and } \\
& \qquad \operatorname{det}\left[\mathbf{K}_{\mathrm{OC}}-\left(\omega_{\mathrm{OC}}\right)^{2} \mathbf{M}\right]=0
\end{aligned}
$$

Figure 2a illustrates the amplitude response $\left|\underline{H}_{\mathrm{sh}}(\Omega)\right|=$ $\left|\underline{H}_{\mathrm{RL}_{\mathrm{opt}}}\right|$ and phase response $\varphi_{\mathrm{sh}}(\Omega)=\varphi_{\mathrm{RL}}{ }_{\mathrm{opt}}$, (see Eq. (20)). The optimal shunt tuning (solid line) attenuates $-22.52 \mathrm{~dB}$ compared to the amplitude response $\left|\underline{H}_{\mathrm{OC}}\right|$ with open circuit (dashed line). Furthermore, Figure 2a shows the response function $\left|\underline{H}_{\mathrm{b}}\right|$ of the beam without attached piezoelectric transducers, its mathematical derivation has been neglected in this paper. Due to the transducers the structure stiffness increases and the first eigenfrequencies $f_{\mathrm{OC}, 1}$ and $f_{\mathrm{SC}, 1}$ are higher than the original first eigenfrequency $f_{\mathrm{b}, 1}=66.2 \mathrm{~Hz}$ of the beam. At $f_{\mathrm{b}, 1}$ the reduction of the amplitude response is $-24.38 \mathrm{~dB}$ compared to the resonance amplitude $\left|\underline{H}_{\mathrm{b}}\right|$ of the beam.

With regard to experimental applications, usually $L$ needs to be in the range of several Henry. This is realized with electrical networks containing operational amplifiers, resistances and a capacitance, also know as gyrators. The circuit simulates the impedance of an inductance by inverting the impedance of the capacitance $C_{4}$. Figure $2 \mathrm{~b}$ shows a realization of such a circuit. Simplified, the circuit shows the same characteristic like an ideal inductor [13], with the value

$$
L=\frac{R_{1} R_{3} R_{5} C_{4}}{R_{2}}
$$

The required values for $L$ are realized with $R_{2}=R_{3}=$ $1 \mathrm{kOhm}, R_{5}=20 \mathrm{kOhm}, C_{4}=1 \mu \mathrm{F}$ and $R_{1}$ for adjusting $L$.

\subsection{Beam with tuned mass damper TMD}

To obtain the best vibration attenuation for the first eigenmode, the TMD is placed at $x_{\mathrm{T}}=l_{\mathrm{b}} / 2$ (see Fig. 3 ).

The TMD is modeled as one degree of freedom system with mass $m_{\mathrm{T}}$ and its displacement $z_{\mathrm{T}}(t)$ that is connected to the beam with a linear damper and a linear spring. The damping coefficient is $b_{\mathrm{T}}$ and the spring's stiffness is $k_{\mathrm{T}}$. Equation (27) shows the equation of motion for the TMD.

$$
\begin{aligned}
m_{\mathrm{T}} \ddot{z}_{\mathrm{T}}(t)=b_{\mathrm{T}}\left(\dot{w}\left(x_{\mathrm{F}}, t\right)-\dot{z}_{\mathrm{T}}(t)\right)+ & k_{\mathrm{T}}\left(w\left(x_{\mathrm{F}}, t\right)\right. \\
& \left.-z_{\mathrm{T}}(t)\right)=F_{\mathrm{T}}(t)
\end{aligned}
$$

where $F_{\mathrm{T}}(t)$ is the resulting force of the TMD acting on the beam and on the mass $m_{\mathrm{T}}$. With $\mathbf{M}_{\mathrm{b}}$ and $\mathbf{K}_{\mathrm{b}}$ from Equations (7) and (9) the equation of motion for the beam only is given by

$$
\begin{aligned}
\mathbf{M}_{\mathrm{b}} \ddot{\mathbf{r}}(t)+\mathbf{D}_{\mathrm{b}} \dot{\mathbf{r}}(t)+\mathbf{K}_{\mathrm{b}} \mathbf{r}(t) & =\mathbf{B}_{\mathrm{F}}\left(F(t)-F_{\mathrm{T}}(t)\right) \\
\text { with } \quad \mathbf{D}_{\mathrm{b}} & =\gamma_{1} \mathbf{M}_{\mathrm{b}}+\gamma_{2} \mathbf{K}_{\mathrm{b}} .
\end{aligned}
$$



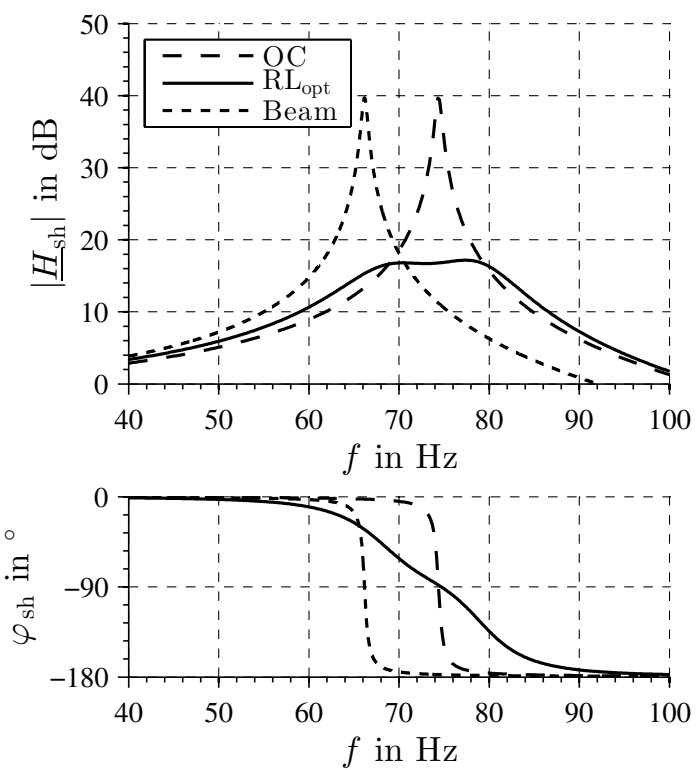

(a)

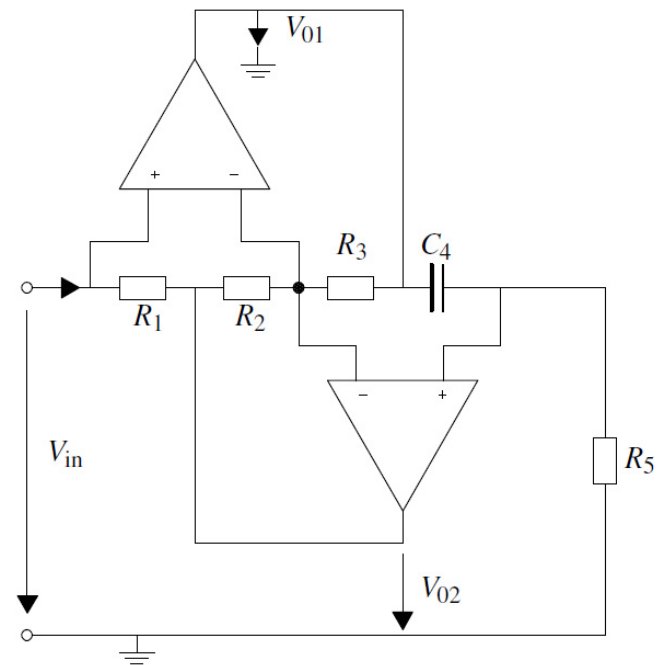

(b)

Fig. 2. (a) Amplitude and phase response $\left|\underline{H}_{\mathrm{OC}}\right|$ and $\varphi_{\mathrm{OC}}$ of the beam with open circuit electrodes, $\left|\underline{H}_{\mathrm{RL}} L_{\mathrm{opt}}\right|$ and $\varphi_{\mathrm{R} L_{\mathrm{opt}}}$ of the beam with optimal resonant shunt with $l_{\mathrm{p}}=40 \mathrm{~mm}, C_{\mathrm{p}}=151.8 \mathrm{nF}, h_{\mathrm{p}}=0.4 \mathrm{~mm}, R_{\mathrm{opt}}=3.7 \mathrm{kOhm}$ and $L_{\mathrm{opt}}=29.1 \mathrm{H},\left|\underline{H}_{\mathrm{b}}\right|$ and $\varphi_{\mathrm{b}}$ of the beam only, (b) circuit synthetic inductance.

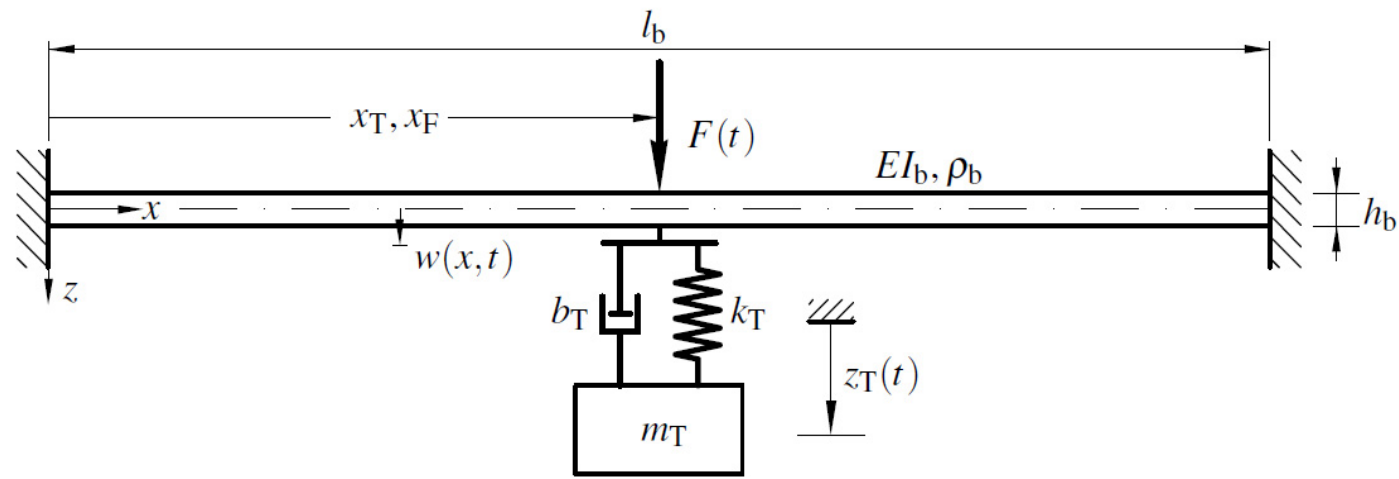

Fig. 3. Beam with tuned mass damper.

\subsubsection{State space model}

Equations (27) and (28) are transferred into first order differential equations to obtain a state space model formulation. The complete model of the coupled mechanical systems (TMD) can be written as

$$
\begin{aligned}
\dot{\mathbf{x}}_{\mathrm{TMD}} & =\mathbf{A}_{\mathrm{TMD}} \mathbf{x}_{\mathrm{TMD}}+\mathbf{B}_{\mathrm{TMD}} u_{\mathrm{TMD}} \\
y_{\mathrm{TMD}} & =\mathbf{C}_{\mathrm{TMD}} \mathbf{x}_{\mathrm{TMD}}+D_{\mathrm{TMD}} u_{\mathrm{TMD}}
\end{aligned}
$$

with the $[(2 K+2) \times(2 K+2)]$ system matrix and the $[(2 K+2) \times 1]$ input matrix

$$
\mathbf{B}_{\mathrm{TMD}}=\left[\begin{array}{c}
\mathbf{0}^{K \times 1} \\
\mathbf{M}_{\mathrm{b}}^{-1} \mathbf{B}_{\mathrm{F}} \\
0 \\
0
\end{array}\right]
$$

All state variables are contained in the $[(2 K+2) \times 1]$ state vector $\mathbf{x}_{\mathrm{TMD}}$. The input $u_{\mathrm{TMD}}$ is the force $F(t)$ and the output $y_{\mathrm{TMD}}$ is the beam displacement at $w\left(x_{\mathrm{F}}, t\right)$.

$$
\mathbf{x}_{\mathrm{TMD}}=\left[\begin{array}{c}
\mathbf{r}(t) \\
\dot{\mathbf{r}}(t) \\
q(t) \\
\dot{q}(t)
\end{array}\right], \quad u_{\mathrm{TMD}}=F(t), \quad y_{\mathrm{TMD}}=w\left(x_{\mathrm{F}}, t\right)
$$




$$
\mathbf{A}_{\mathrm{TMD}}=\left[\begin{array}{cccc}
\mathbf{0}^{K \times K} & \mathbf{I}^{K \times K} & \mathbf{0}^{K \times 1} & \mathbf{0}^{K \times 1} \\
-\mathbf{M}_{\mathrm{b}}^{-1}\left(\mathbf{K}_{\mathrm{b}}-\Psi\left(x_{\mathrm{T}}\right)^{\top} \mathbf{B}_{\mathrm{F}} k_{\mathrm{T}}\right) & -\mathbf{M}_{\mathrm{b}}^{-1}\left(\mathbf{D}_{\mathrm{b}}-\Psi\left(x_{\mathrm{T}}\right)^{\top} \mathbf{B}_{\mathrm{F}} b_{\mathrm{T}}\right) & k_{\mathrm{T}} \Psi\left(x_{\mathrm{T}}\right)^{\top} & b_{\mathrm{T}} \Psi\left(x_{\mathrm{T}}\right)^{\top} \\
\mathbf{0}^{1 \times K} & \mathbf{0}^{1 \times K} & 0 & 1 \\
k_{\mathrm{T}} m_{\mathrm{T}}^{-1} \Psi\left(x_{\mathrm{T}}\right)^{\top} & b_{\mathrm{T}} m_{\mathrm{T}}^{-1} \Psi\left(x_{\mathrm{T}}\right)^{\top} & -k_{\mathrm{T}} m_{\mathrm{T}}^{-1} & -b_{\mathrm{T}} m_{\mathrm{T}}^{-1}
\end{array}\right]
$$

To obtain the displacement $w\left(x_{\mathrm{F}}, t\right)$, a transformation from generalized coordinates $r(t)$ to physical coordinates $x(t)$ is performed with the vector of trial functions $\boldsymbol{\Psi}\left(x_{\mathrm{F}}\right)$. Using the particular integral approach the complex transfer function of the beam with TMD for the beam displacement amplitude $\hat{w}\left(x_{\mathrm{F}}=l_{\mathrm{b}} / 2\right)$ in frequency domain results in

$$
\begin{aligned}
\underline{H}_{\mathrm{TMD}}(\Omega) & =\frac{\widehat{w}\left(x_{\mathrm{F}}\right)}{\widehat{F}} \\
& =\mathbf{C}_{\mathrm{TMD}}\left(j \Omega \mathbf{I}-\mathbf{A}_{\mathrm{TMD}}\right)^{-1} \mathbf{B}_{\mathrm{TMD}}+D_{\mathrm{TMD}}
\end{aligned}
$$

with its amplitude and phase response $\left|\underline{H}_{\mathrm{TMD}}(\Omega)\right|$ and $\varphi_{\mathrm{TMD}}(\Omega)=\arg \left\{\underline{H}_{\mathrm{TMD}}(\Omega)\right\}$.

\subsection{Optimal tuning parameters}

Comparable to the resonant shunt, the TMD needs to be tuned to the vibrating structure. Therefore $b_{\mathrm{T}}$ and $k_{\mathrm{T}}$ are chosen according to [14] as

$k_{\mathrm{T}, \mathrm{opt}}=m_{\mathrm{T}} \omega_{\mathrm{T}}^{2} \quad$ with $\quad \omega_{\mathrm{T}}=\frac{\omega_{\mathrm{b}, 1}}{1+\mu_{\mathrm{T}}} \quad$ and $\quad \mu_{\mathrm{T}}=\frac{m_{\mathrm{T}}}{m_{\mathrm{osc}}}$

and

$$
b_{\mathrm{T}, \mathrm{opt}}=2 \zeta_{\mathrm{opt}} \sqrt{k_{\mathrm{T}} m_{\mathrm{T}}} \quad \text { with } \quad \zeta_{\mathrm{opt}}=\sqrt{\frac{1}{2} \frac{\mu_{\mathrm{T}}}{1+\mu_{\mathrm{T}}}}
$$

In Equation $(34), \mu_{\mathrm{T}}$ is the ratio of $m_{\mathrm{T}}$ and the oscillating mass $m_{\mathrm{osc}}$ of the beam. The oscillating mass $m_{\mathrm{osc}}$ is obtained by equalizing the kinetic energy of a one degree of freedom oscillator and the beam in the mounting point of the TMD. The mass is calculated to be $0.12 \mathrm{~kg}$ with

$$
m_{\mathrm{osc}}=\int_{0}^{l_{\mathrm{b}}} \eta_{\mathrm{b}} \Phi^{2}(x) \mathrm{d} x
$$

where $\Phi(x)$ is the normalized first modeshape of the beam.

Figure 4 shows the amplitude and phase response $\left|\underline{H}_{\mathrm{TMD}}(f)\right|=\left|\underline{H}_{\mathrm{TMD}}\right|$ and $\varphi_{\mathrm{TMD}}(f)=\varphi_{\mathrm{TMD}}$, see Equation (33) and the frequency response $\left|\underline{H}_{\mathrm{b}}\right|$ of the beam only. The optimal TMD tuning (solid line) attenuates $25.3 \mathrm{~dB}$ compared to the amplitude response of the beam (dashed line). The attenuation at $f_{\mathrm{b}, 1}$ is $-25.65 \mathrm{~dB}$.

\section{Uncertainty quantification}

In this paper, the vibration attenuation capability with respect to the used additional masses on the beam
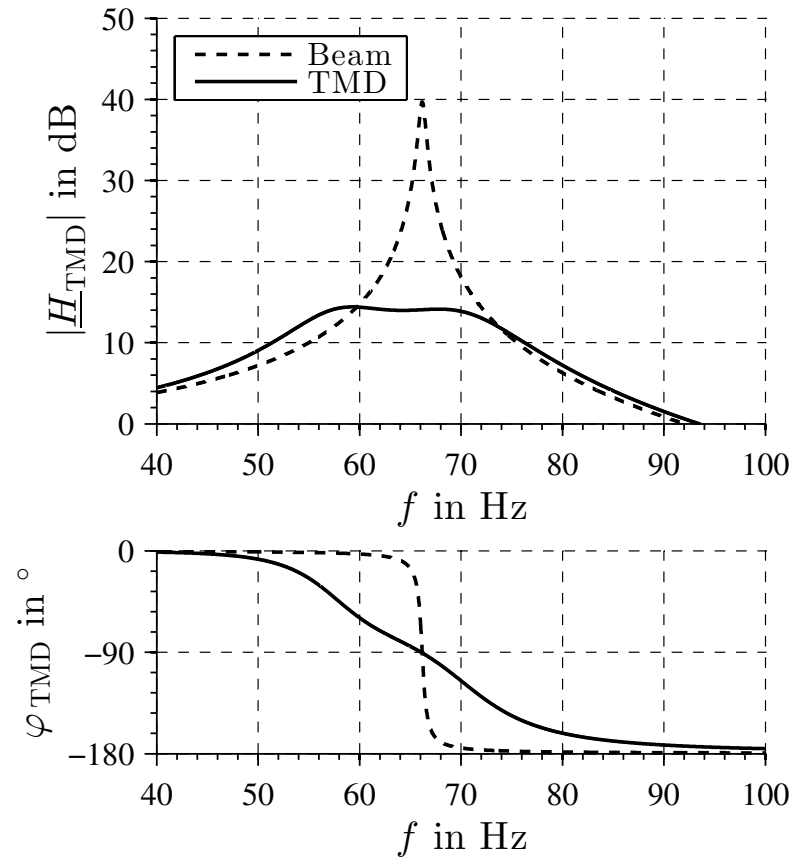

Fig. 4. Amplitude and phase response $\left|\underline{H}_{\mathrm{TMD}}\right|$ and $\varphi_{\mathrm{TMD}}$ of the beam with optimal TMD with $\mu_{\mathrm{T}}=0.07, k_{\mathrm{T}}=$ $1.3 \mathrm{kN} . \mathrm{m}^{-1}, b_{\mathrm{T}}=1.22 \mathrm{Ns}^{-1},\left|\underline{H}_{\mathrm{b}}\right|$ and $\varphi_{\mathrm{b}}$ of the beam only.

for a TMD and a resonant shunt are compared and effects due to parametric uncertainty are presented. Uncertainty in vibration attenuation arising from uncertain parameters in resonant shunt and TMD is discussed in a simple but consistent and transparent way. A general approach to describe and evaluate uncertainty in load carrying systems is presented in reference [15-17]. This approach uses a matrix to assign uncertainty categories to all relevant system properties for a certain state at a certain time, e.g. in the design or operating process. According to [16], geometrical, material, electrical, economical and other properties are of interest. Table 1 shows the relevant properties for the beam clamped at both ends with resonant shunt or TMD after completing the definition phase in the design process at the point of time $t_{\text {def }}$ subjected to parametric uncertainty.

Uncertainty for each property may be divided into three categories:

\subsection{Stochastic uncertainty}

Stochastic uncertainty is given if a non-deterministic value of an arbitrary property is approximated 
Table 1. Matrix after completing the definition phase for vibration attenuation.

\begin{tabular}{|c|c|c|c|c|c|c|}
\hline & \multicolumn{3}{|c|}{ Point in time: $t_{\mathrm{def}}$} & \multicolumn{3}{|c|}{ Uncertainty } \\
\hline Property & & Variable & Unit & Stochastic & Estimated & Unknown \\
\hline \multirow[t]{6}{*}{ Geometry } & Length beam & $l_{\mathrm{b}}$ & $\mathrm{mm}$ & - & $\overline{-}$ & 400 \\
\hline & Width beam & $a_{\mathrm{b}}$ & $\mathrm{mm}$ & - & - & 50 \\
\hline & Thickness beam & $h_{\mathrm{b}}$ & $\mathrm{mm}$ & - & - & 2 \\
\hline & Length piezo & $l_{\mathrm{p}}$ & $\mathrm{mm}$ & - & - & $l_{\mathrm{p}, 0}$ \\
\hline & Width piezo & $a_{\mathrm{p}}$ & $\mathrm{mm}$ & - & - & 50 \\
\hline & Thickness piezo & $h_{\mathrm{p}}$ & $\mathrm{mm}$ & - & - & $h_{\mathrm{p}, 0}$ \\
\hline \multirow[t]{6}{*}{ Material } & Density steel & $\rho_{\mathrm{b}}$ & $\mathrm{kg} \cdot \mathrm{m}^{-3}$ & - & - & 7838 \\
\hline & Young's modulus steel & $E_{\mathrm{b}}$ & $\mathrm{GPa}$ & - & - & 208 \\
\hline & Density piezo & $\rho_{\mathrm{p}}$ & $\mathrm{kg} \cdot \mathrm{m}^{-3}$ & - & - & 7800 \\
\hline & Young's modulus piezo & $E_{\mathrm{p}}$ & $\mathrm{GPa}$ & - & - & 62.9 \\
\hline & Dielectric constant & $\beta_{\mathrm{r}, 33}^{\mathrm{S}}$ & - & - & - & 857 \\
\hline & Piezoelectric coeff. & $d_{31}$ & $\mathrm{mV}^{-1}$ & - & $d_{31,0} \pm 0.1 d_{31,0}$ & $-1.74 \times 10^{-10}$ \\
\hline \multirow{3}{*}{ Mechanical } & Mass TMD & $\overline{m_{\mathrm{T}}}$ & $\mathrm{kg}$ & - & $m_{\mathrm{T}, 0} \pm 0.1 m_{\mathrm{T}, 0}$ & $\overline{m_{\mathrm{T}, 0}}$ \\
\hline & Damping coeff. TMD & $b_{\mathrm{T}}$ & N.s.m ${ }^{-1}$ & - & $b_{\mathrm{T}, \mathrm{opt}, 0} \pm 0.3 b_{\mathrm{T}, \mathrm{opt}, 0}$ & $b_{\mathrm{T}, \mathrm{opt}, 0}$ \\
\hline & Stiffness TMD & $k_{\mathrm{T}}$ & N.m ${ }^{-1}$ & - & $k_{\mathrm{T}, \mathrm{opt}, 0} \pm 0.15 k_{\mathrm{T}, \mathrm{opt}, 0}$ & $k_{\mathrm{T}, \mathrm{opt}, 0}$ \\
\hline \multirow[t]{5}{*}{ Electrical } & Inductance shunt & $L$ & $\mathrm{H}$ & - & $L_{\mathrm{opt}, 0} \pm 0.1 L_{\mathrm{opt}, 0}$ & $L_{\mathrm{opt}, 0}$ \\
\hline & Resistance shunt & $R$ & Ohm & - & $R_{\mathrm{opt}, 0} \pm 0.1 R_{\mathrm{opt}, 0}$ & $R_{\mathrm{opt}, 0}$ \\
\hline & Resistance gyrator & $R_{\mathrm{i}}$ & Ohm & - & $R_{\mathrm{i}, 0} \pm 0.1 R_{\mathrm{i}, 0}$ & $R_{\mathrm{i}, 0}$ \\
\hline & Capacitance piezo & $C_{\mathrm{p}}$ & $\mathrm{F}$ & - & $C_{\mathrm{p}, 0} \pm 0.2 C_{\mathrm{p}, 0}$ & $C_{\mathrm{p}, 0}$ \\
\hline & Capacitance gyrator & $C_{4}$ & $\mathrm{~F}$ & - & $C_{4,0} \pm 0.05 C_{4,0}$ & $C_{4,0}$ \\
\hline Economical & not specified & - & - & $\overline{-}$ & $\overline{-}$ & $\overline{-}$ \\
\hline Other & not specified & - & - & $\overline{-}$ & $\overline{-}$ & - \\
\hline
\end{tabular}

probabilistically, e.g. from a sufficient number of statistically independent experiments or field data. Hence, distribution functions are known or can be calculated and the parameter variation can be described with mean value $\mu$ and standard deviation $\sigma$. In this paper, no stochastic uncertainty is taken into account.

\subsection{Estimated uncertainty}

Estimated uncertainty is given if a non-deterministic value of an arbitrary property symbolized by is approximated from experience or literature. For each value, a lower limit ${ }^{-}$and an upper limit ${ }^{+}$can be specified, so $\overline{\bar{i}}=\left[\mathbf{i}^{-} ; \bar{i}^{+}\right]$.

For the considered TMD and as an example, estimated uncertainty $\bar{m}_{\mathrm{T}}=\left[m_{\mathrm{T}}^{-} ; m_{\mathrm{T}}^{+}\right]$for the mass $m_{\mathrm{T}}$ with a lower limit $m_{\mathrm{T}}^{-}=m_{\mathrm{T}, 0}-0.1 m_{\mathrm{T}, 0}$ and an upper limit $m_{\mathrm{T}}^{+}=m_{\mathrm{T}, 0}+0.1 m_{\mathrm{T}, 0}$, with the tolerance of $\pm 10 \%$ estimated by the authors. Lower and upper limits of other parameters are calculated accordingly. The stiffness $k_{\mathrm{T}}$ is estimated by the authors to vary up to a maximum of $\pm 15 \%$. Damping $b_{\mathrm{T}}$ of a TMD may vary up to the maximum of $\pm 30 \%$ [18].

As for the resonant shunt, the maximum deviation of the piezoelectric coefficient $d_{31}$ varies up to $\pm 10 \%$ based on [19]. The capacitance $C_{\mathrm{p}}$ is affected by the transducer's geometry and the bonding to the beam. In general, only the relative permittivity at constant strain $\beta_{\mathrm{r}, 33}^{\mathrm{S}}$ and at constant stress $\beta_{\mathrm{r}, 33}^{\mathrm{T}}$, i.e. mechanically blocked or free, are given by the manufacturer. However, a piezoelectric transducer bonded to a host structure is not represented correctly by neither of these constants. Uncertainty result- ing form material, bonding and geometry are condensed in the estimated uncertainty $\bar{C}_{\mathrm{p}}$. The capacitance $C_{\mathrm{p}}$ of piezoelectric transducer may vary up to $\pm 20 \%$ (manufacturer: Physik Instrument - PI). The capacitance $C_{4}$ used in the gyrator circuit in Figure $2 \mathrm{~b}$ may vary up to the maximum of $\pm 5 \%$, and a resistance $R$ may vary up to the maximum of $\pm 10 \%$, (manufacturer: WIMA, Multicomp). The maximum deviation of inductance $L$ is $\pm 10 \%$ calculated with Equation (26) according to [20].

\subsection{Unknown uncertainty}

Unknown uncertainty is given if no declaration regarding any uncertainty is made and, in terms of parametric uncertainty, the parameter is considered to be deterministic. In that case, one assumed single value $i_{0}$ of an arbitrary property symbolized by is specified and equivalence $=m_{0}$ is given. For the resonant shunt and TMD approach, Figures 1 and 3, all geometrical parameters, such as the length $l_{\mathrm{b}}$ and $l_{\mathrm{p}}$ of the beam and the transducer, the width $a_{\mathrm{b}}$ and $a_{\mathrm{p}}$ of the beam and the transducer as well as the thickness $h_{\mathrm{b}}$ and $h_{\mathrm{p}}$ of the beam and transducer are considered to be deterministic. Furthermore, no uncertainty in the material parameters density $\rho_{\mathrm{b}}$ and $\rho_{\mathrm{p}}$ as well as Young's modulus $E_{\mathrm{b}}$ and $E_{\mathrm{p}}$ is taken into consideration.

\section{Numerical simulation of vibration attenuation}

In this section, the effects of estimated parameter uncertainty on the vibration attenuation performance of the 
Table 2. Estimated uncertainty for resonant shunt and TMD.

\begin{tabular}{cccc}
\hline Case & resonant shunt & Case & TMD \\
\hline $\mathrm{A} 1$ & $\bar{C}_{\mathrm{p}}=\left[C_{\mathrm{p}}^{-} ; C_{\mathrm{p}}^{+}\right]$ & $\mathrm{B} 1$ & $\bar{k}_{\mathrm{T}}=\left[k_{\mathrm{T}}^{-} ; k_{\mathrm{T}}^{+}\right]$ \\
\hline $\mathrm{A} 2$ & $\bar{d}_{31}=\left[d_{31}^{-} ; d_{31}^{+}\right]$ & $\mathrm{B} 2$ & $\bar{m}_{\mathrm{T}}=\left[m_{\mathrm{T}}^{-} ; m_{\mathrm{T}}^{+}\right]$ \\
\hline $\mathrm{A} 3$ & $\bar{L}=\left[L^{-} ; L^{+}\right]$ & $\mathrm{B} 3$ & $\bar{b}_{\mathrm{T}}=\left[b_{\mathrm{T}}^{-} ; b_{\mathrm{T}}^{+}\right]$ \\
\hline $\mathrm{A} 4$ & $\bar{R}=\left[R^{-} ; R^{+}\right]$ & $\mathrm{B} 4$ & $\begin{array}{c}{\left[\left(k_{\mathrm{T}}^{+}, m_{\mathrm{T}}^{-}, b_{\mathrm{T}}^{+}\right) ;\right.} \\
\left.\left(k_{\mathrm{T}}^{-}, m_{\mathrm{T}}^{+}, b_{\mathrm{T}}^{-}\right)\right]\end{array}$ \\
\hline $\mathrm{A} 5$ & {$\left[\left(C_{\mathrm{p}}^{+}, d_{31}^{-}, L^{+}, R^{+}\right) ;\right.$} \\
$\left.\left(C_{\mathrm{p}}^{-}, d_{31}^{-}, L^{-}, R^{+}\right)\right]$ & - & \\
\hline
\end{tabular}

clamped beam with resonant shunt and TMD are outlined. For the resonant shunt frequency response functions $\underline{H}_{\text {sh }}(f)$, (see Eq. (20)), are calculated for the five cases A1 to A5 (Tab. 2). In case of the TMD, frequency response functions $\underline{H}_{\mathrm{TMD}}(f)$ (see Eq. (33)), are calculated for the four cases B1 to B4.

In case $\mathrm{A} 1$, only the capacitance $C_{\mathrm{p}}$ of the piezoelectric transducers is subject to assumed estimated uncertainty with $\bar{C}_{\mathrm{p}}=\left[C_{\mathrm{p}}^{-} ; C_{\mathrm{p}}^{+}\right]=\left[C_{\mathrm{p}, 0}-0.2 C_{\mathrm{p}, 0} ; C_{\mathrm{p}, 0}+0.2 C_{\mathrm{p}, 0}\right]$. For all other properties in Table 1 , unknown uncertainty is assumed. In case B1, only the stiffness $\bar{k}_{\mathrm{T}}=\left[k_{\mathrm{T}}^{-} ; k_{\mathrm{T}}^{+}\right]=$ $\left[k_{\mathrm{T}, \mathrm{opt}, 0}-0.15 k_{\mathrm{T}, \mathrm{opt}, 0} ; k_{\mathrm{T}, \mathrm{opt}, 0}+0.15 k_{\mathrm{T}, \mathrm{opt}, 0}\right]$ is subject to assumed estimated uncertainty. In similar ways, cases A2 to A4 for the resonant shunt and cases B2 to B3 for the TMD take into account estimated uncertainty only for the simple properties $d_{31}, L$ and $R$ for the resonant shunt and $m_{\mathrm{T}}$ and $b_{\mathrm{T}}$ for the TMD separately. Cases A5 and B4 examine the influence of estimated uncertainty in $C_{\mathrm{p}}, d_{31}, L$ and $R$ for the resonant shunt and in $k_{\mathrm{T}}$, $m_{\mathrm{T}}$ and $b_{\mathrm{T}}$ for the TMD simultaneously. The results are presented in Sections 4.1 and 4.2.

In Section 4.3 the vibration attenuation performance of resonantly shunted transducers for different dimensions and TMD for different masses $m_{\mathrm{T}, 0}$ are compared. By varying the transducer length $l_{\mathrm{p}, 0}$ and thickness $h_{\mathrm{p}, 0}$, different masses of piezoelectric ceramic $m_{\mathrm{p}, 0}$ are given, as seen in Figure 1 . The masses $m_{\mathrm{p}, 0}$ and $m_{\mathrm{T}, 0}$ are considered as additional masses with respect to the beam's mass $m_{\mathrm{osc}}$. Frequency response functions $\underline{H}_{\mathrm{sh}}(f)$ and $\underline{H}_{\mathrm{TMD}}(f)$ according to Equation (20) and Equation (33) are calculated for different additional masses. Furthermore, $\underline{H}_{\mathrm{sh}}(f)$ and $\underline{H}_{\mathrm{TMD}}(f)$ are calculated for different additional masses for cases A5 and $\mathrm{B} 4$. The vibration attenuation performance of both approaches is compared by the amplitude response $\left|\underline{H}_{\mathrm{sh}}\left(f_{\mathrm{b}, 1}\right)\right|$ and $\left|\underline{H}_{\mathrm{TMD}}\left(f_{\mathrm{b}, 1}\right)\right|$ at the beam's first eigenfrequency $f_{\mathrm{b}, 1}$ and the maximum amplitude response $\left|\underline{H}_{\mathrm{sh}}\right|_{\max }$ and $\left|\underline{H}_{\mathrm{TMD}}\right|_{\max }$ within the range of the first eigenfrequency $f_{\mathrm{OC}, 1}$ with open circuit and $f_{\mathrm{b}, 1}$, respectively.

\subsection{Vibration attenuation with resonant shunt}

The vibration attenuation under the influence of estimated uncertainty is described in cases A1 to A5, Table 2. According to Table 1, unknown uncertainty is assumed exemplary for a resonant shunt with $l_{\mathrm{p}, 0}=40 \mathrm{~mm}$,
$C_{\mathrm{p}, 0}=151.8 \mathrm{nF}, h_{\mathrm{p}, 0}=0.4 \mathrm{~mm}, L_{0}=L_{\mathrm{opt}}=29.1 \mathrm{H}$ and $R_{0}=R_{\text {opt }}=3.7 \mathrm{kOhm}$. For all cases A1 to A5, the amplitude and phase responses for varying $\bar{C}_{\mathrm{p}}, \bar{d}_{31}, \bar{L}$ and $\bar{R}$ are compared to amplitude and phase responses for $C_{\mathrm{p}, 0}, d_{31,0}, L_{0}$ and $R_{0}$. For simplification, the amplitude and phase response in Equation (20) are $\left|\underline{H}_{\mathrm{sh}}(f)\right|=\left|\underline{H}_{\mathrm{sh}}\right|$ and $\varphi_{\mathrm{sh}}(f)=\varphi_{\mathrm{sh}}$.

\section{Case A1}

Figure 5a shows the amplitude $\left|\underline{H}_{\mathrm{sh}}\right|$ and phase $\varphi_{\text {sh }}$ response for $\bar{C}_{\mathrm{p}}=\left[C_{\mathrm{p}}^{-} ; C_{\mathrm{p}}^{+}\right]=[121.44 \mathrm{nF} ; 182.16 \mathrm{nF}]$ compared to $C_{\mathrm{p}, 0}=151.8 \mathrm{nF}$ if uncertainty is unknown. The capacitance $C_{\mathrm{p}}$ may have three effects on the vibration attenuation performance. First, it affects the amount of charge induced in the transducers electrodes for a given deformation. Second, it affects the effective structural stiffness and, thus, the open circuit resonance frequencies. Third, it affects the resonance frequency of the shunt circuit and, hence, the tuning of the resonant shunt.

$C_{\mathrm{p}}^{+}$decreases the first structural resonance frequency and $C_{\mathrm{p}}^{-}$increases the resonance frequency according to: $f_{\mathrm{OC}, \mathrm{C}_{\mathrm{p}}^{+}}=0.997 f_{\mathrm{OC}, 0}$ and $f_{\mathrm{OC}, \mathrm{C}_{\mathrm{p}}^{-}}=1.004 f_{\mathrm{OC}, 0}$. The tuning frequency of the shunt changes to $f^{\mathrm{el}, \mathrm{C}_{\mathrm{p}}^{+}}=0.91 f_{e l, 0}$ and $f_{\mathrm{el}, \mathrm{C}_{\mathrm{p}}^{-}}=1.12 f_{\mathrm{el}, 0}$. Hence, $\bar{C}_{\mathrm{p}}$ mainly results in detuning of the resonant shunt increasing the maximum amplitude. Regarding the phase response, $C_{\mathrm{p}}^{-}$shifts the frequency where the phases crosses $-90^{\circ}$ to a lower frequency. For $C_{\mathrm{p}}^{-}$the crossing frequency increases.

\section{Case A2}

Figure $5 \mathrm{~b}$ shows the amplitude $\left|\underline{H}_{\text {sh }}\right|$ and phase $\varphi_{\text {sh }}$ response for estimated uncertainty $\overline{\bar{d}}_{31}=\left[d_{31}^{-} ; d_{31}^{+}\right]=$ $\left[1.56 \times 10^{-10} \mathrm{~m} . \mathrm{V}^{-1} ; 1.91 \times 10^{-10} \mathrm{~m} . \mathrm{V}^{-1}\right]$ compared to $d_{31,0}=-1.74 \times 10^{-10} \mathrm{~m} . \mathrm{V}^{-1 s}$ if uncertainty is unknown. The higher the piezoelectric coefficient $d_{31}$, the higher the amount of mechanical energy converted to electrical energy is. Compared to the capacitance $C_{\mathrm{p}}$, it does not detune the shunt, but affecst the open circuit frequencies $f_{\text {OC }}$ due to stiffness change in $\mathbf{K}_{\mathrm{OC}}$ according to Equations (5) and (14a). Figure 5b shows an increase of amplitudes for $d_{31}^{-}$and a decrease for $d_{31}^{+}$, the change in the first resonance frequency $f_{\mathrm{OC}, \bar{d}_{31}}$ is negligible. There is no distinct phase shift in the resonance frequency either.

\section{Case A3}

Figure $6 \mathrm{a}$ shows the amplitude $\left|\underline{H}_{\text {sh }}\right|$ and phase $\varphi_{\text {sh }}$ response for $\bar{L}=\left[L^{-} ; L^{+}\right]=[26.19 \mathrm{H} ; 32.01 \mathrm{H}]$ compared to $L_{0}=29.1 \mathrm{H}$ if uncertainty is unknown. The tuning frequency of the shunt changes to $f_{\mathrm{el,} \mathrm{L}^{+}}=0.97 f_{e l, 0}$ and $f_{\mathrm{el}, \mathrm{L}^{-}}=1.07 f_{e l, 0}$. Compared to the effect of an uncertain capacitance $\bar{C}_{\mathrm{p}}$ the shunt inductance $\bar{L}$ effects the tuning frequency of the shunt less due to a smaller assumed 

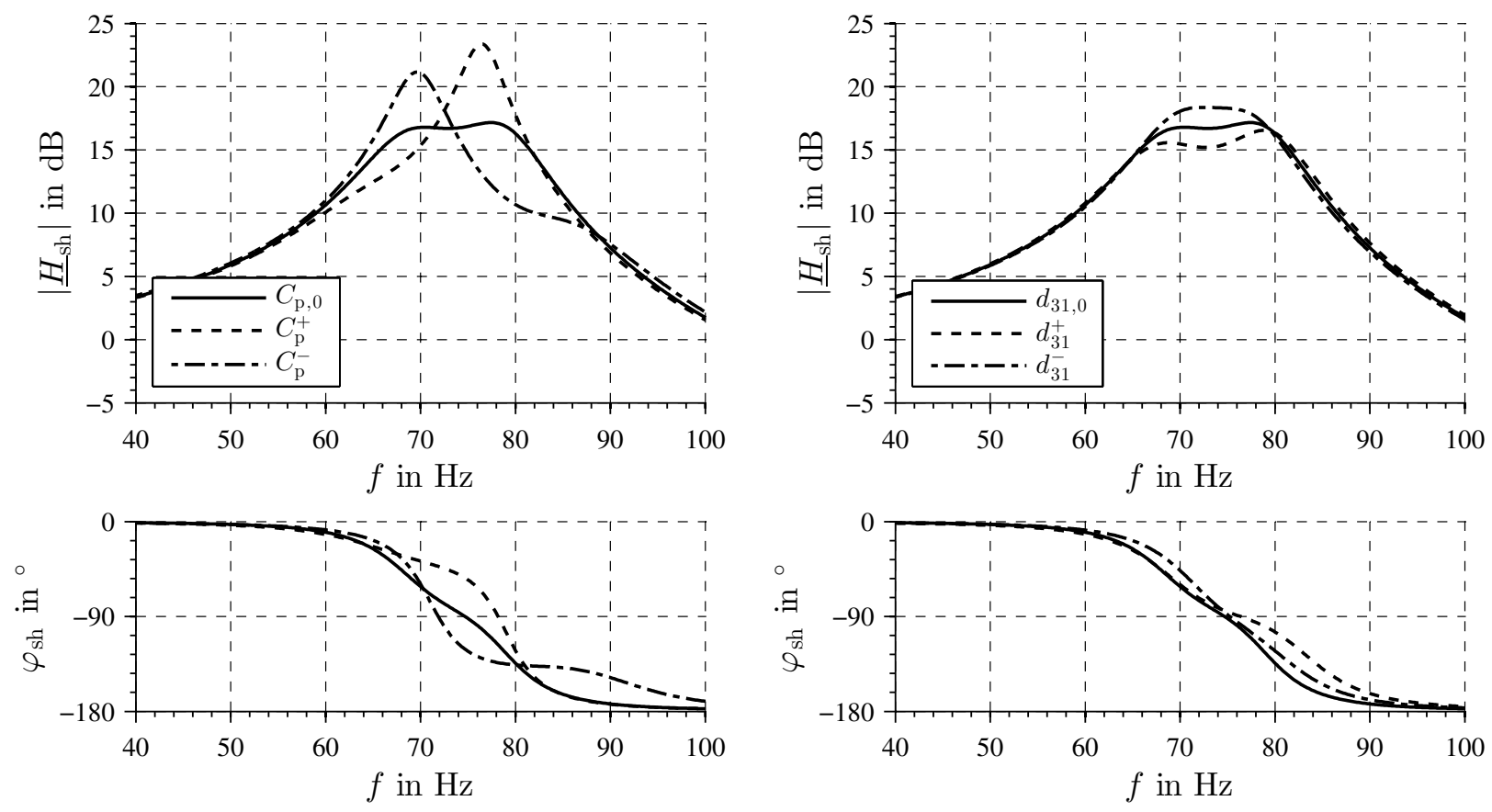

(a)

(b)

Fig. 5. Amplitude and phase response $\left|\underline{H}_{\mathrm{sh}}\right|$ and $\varphi_{\mathrm{sh}}$ of the beam with resonant shunt, (a) case A1: $\bar{C}_{\mathrm{p}}=[121.44 \mathrm{nF} ; 182.16 \mathrm{nF}]$ and $C_{\mathrm{p}, 0}=151.8 \mathrm{nF}$, (b) case A2: $\bar{d}_{31}=\left[1.56 \times 10^{-10} \mathrm{~m} . \mathrm{V}^{-1} ; 1.91 \times 10^{-10} \mathrm{~m} . \mathrm{V}^{-1}\right]$ and $d_{31,0}=-1.74 \times 10^{-10} \mathrm{~m} . \mathrm{V}^{-1}$.

estimated uncertainty of $\pm 10 \%$. Regarding the phase response, $L^{-}$has a minor influence on the $-90^{\circ}$ crossing frequency than $L^{+} . L^{+}$increases the $-90^{\circ}$ crossing frequency.

\section{Case A4}

Figure $6 \mathrm{~b}$ shows the amplitude $\left|\underline{H}_{\mathrm{sh}}\right|$ and phase $\varphi_{\mathrm{sh}}$ response for $\bar{R}=\left[R^{-} ; R^{+}\right]=[3.33 \mathrm{kOhm} ; 4.07 \mathrm{kOhm}]$ compared to $R_{0}=3.7 \mathrm{kOhm}$ if uncertainty is unknown. The amplitudes increase for $R^{+}$. For $R^{-}$the amplitudes mainly decreases between the maximum amplitudes of $\left|H_{\mathrm{sh}}\right|$. The resistance $R$ does not change the tuning frequency of the shunt, hence, $\bar{R}$ has comparable little influence on the attenuation performance and the phase response.

\section{Case A5}

Figure 7 shows the amplitude $\left|\underline{H}_{\mathrm{sh}}\right|$ and phase $\varphi_{\mathrm{sh}}$ response for $C_{\mathrm{p}}^{+}, d_{31}^{-}, L^{+}, R^{+}$and $C_{\mathrm{p}}^{-}, d_{31}^{-}, L^{-}, R^{+}$as well as for $C_{\mathrm{p}, 0}, d_{31,0}, L_{0}, R_{0}$. The combinations are chosen according to the effects of estimated uncertainty on the vibration attenuation as described in Figures 5 and 6 . The investigated combinations both lead to increasing vibration amplitudes. Considering only upper and lower limits is justified since the maximal amplitude in the attenuated frequency range increases or decreases monotonically for deviations from the nominal and optimal parameters within the intervals of estimated uncertainty. The combination $C_{\mathrm{p}}^{-}, d_{31}^{-}, L^{-}, R^{+}$leads to a shift of the tuning frequency $f_{\mathrm{el}}^{+}=1.15 f_{e l, 0}$. The combination $C_{\mathrm{p}}^{+}, d_{31}^{-}, L^{+}, R^{+}$changes the tuning frequency of the shunt to $f_{\mathrm{el}}^{-}=0.84 f_{e l, 0}$. The detuning to $f_{\mathrm{el}}^{-}$shifts the $-90^{\circ}$ crossing frequency in the phase response to a higher frequency, whereas the detuning $f_{\mathrm{el}}^{+}$has minor influence on the phase response. Comparing the maximum amplitude with Figure 5a one can see, the increase of the maximum amplitude is dominated by $C_{\mathrm{p}}^{+}$. The combination $C_{\mathrm{p}}^{+}, d_{31}^{-}, L^{+}, R^{+}$represents the worst with the maximal vibration amplitude in the attenuated frequency range.

The worst case combination $C_{\mathrm{p}}^{+}, d_{31}^{-}, L^{+}, R^{+}$changes the tuning frequency of the shunt to $f_{\mathrm{el}}^{-}=0.84 f_{e l, 0}$, resulting in the maximum detuning and amplitude. The detuning to $f_{\mathrm{el}}^{-}$shifts the $-90^{\circ}$ crossing frequency in the phase response to a higher frequency, whereas the detuning $f_{\mathrm{el}}^{+}$has minor influence on the phase response. Comparing the maximum amplitude with Figure 5a one can see, the increase of the maximum amplitude is dominated by $C_{\mathrm{p}}^{+}$.

\subsection{Vibration attenuation with TMD}

The vibration attenuation under the influence of estimated uncertainty is described in cases B1 to B4, Table 2. 

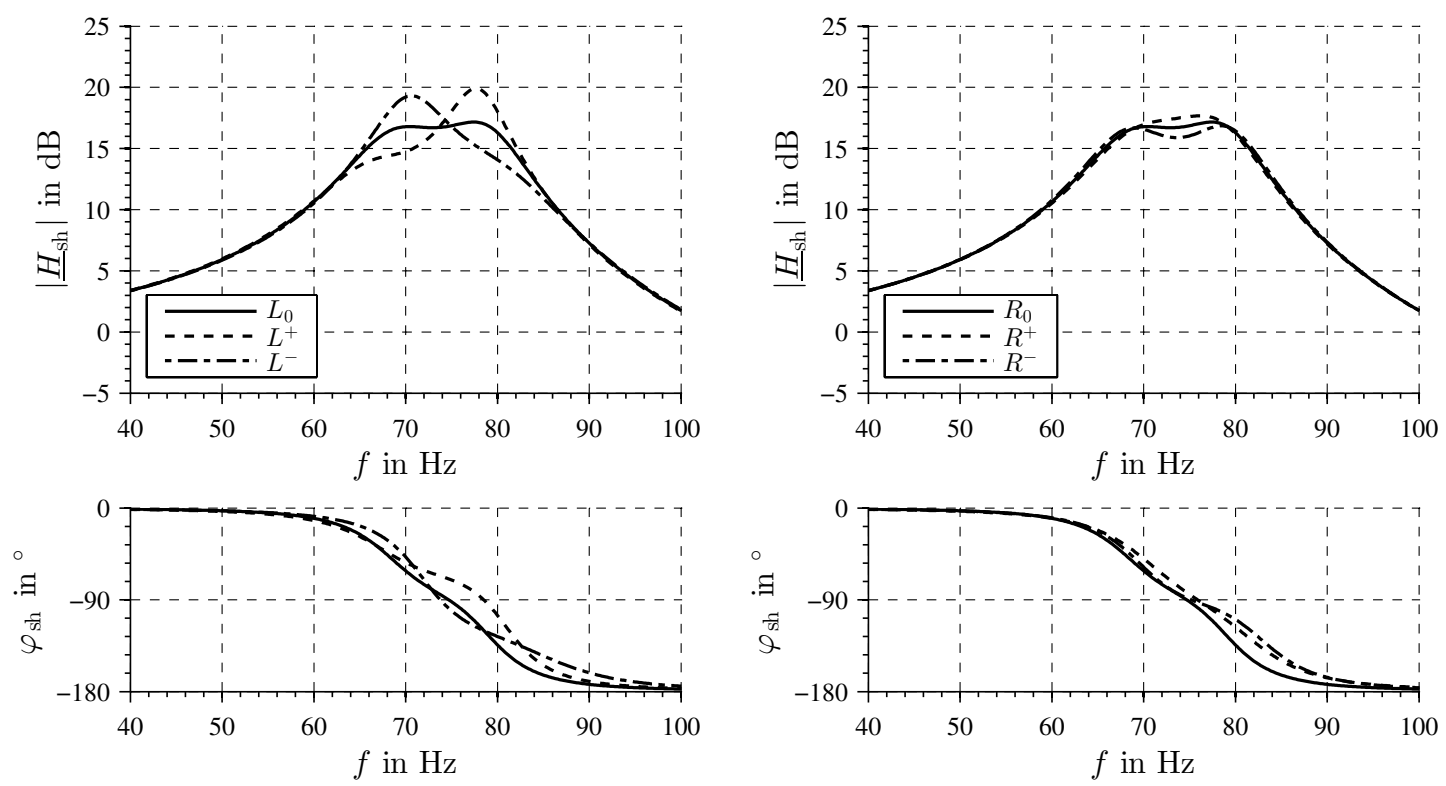

(a)

(b)

Fig. 6. Amplitude and phase response $\left|\underline{H}_{\text {sh }}\right|$ and $\varphi_{\text {sh }}$ of the beam with resonant shunt, (a) case A3: $\bar{L}=[26.19 \mathrm{H} ; 32.01 \mathrm{H}]$ and $L_{0}=29.1 \mathrm{H}$, (b) case A $4: \bar{R}=[3.33 \mathrm{k} \Omega ; 4.07 \mathrm{k} \Omega]$ and $R_{0}=3.7 \mathrm{k} \Omega$.
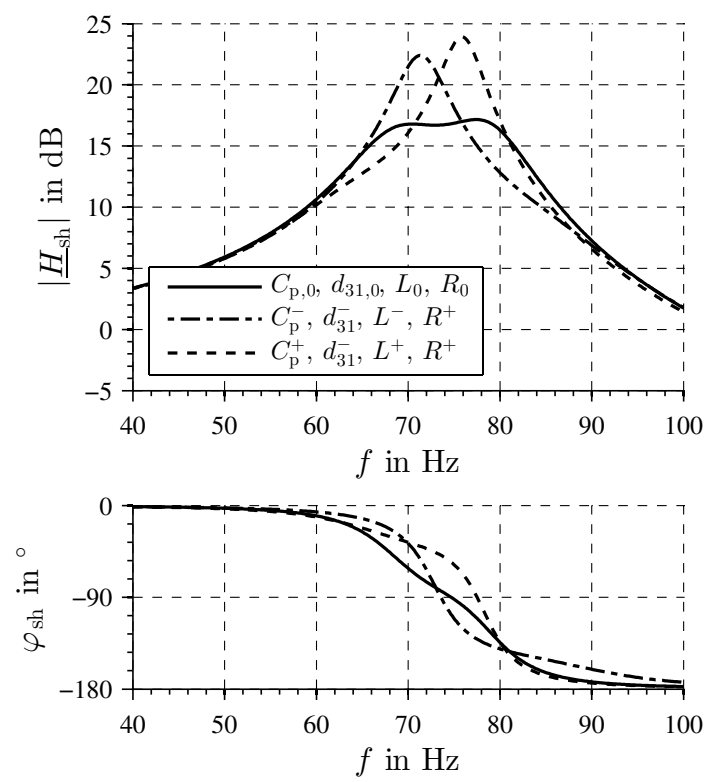

Fig. 7. Amplitude and phase response $\left|\underline{H}_{\mathrm{sh}}\right|$ and $\varphi_{\mathrm{sh}}$ of the beam with resonant shunt for case $\mathrm{A} 5$ and $C_{\mathrm{p}, 0}, d_{31,0}, L_{0}, R_{0}$.

According to Table 1 unknown uncertainty is assumed exemplary for a TMD with $\mu_{\mathrm{T}, 0}=0.07, m_{\mathrm{T}, 0}=0.0087 \mathrm{~kg}$, $k_{\mathrm{T}, 0}=k_{\mathrm{T}, \mathrm{opt}}=1.31 \mathrm{kN} / \mathrm{m}$ and $b_{\mathrm{T}, 0}=b_{\mathrm{T}, \mathrm{opt}}=$ $1.22 \mathrm{Ns} / \mathrm{m}$. For all cases B1 to B4, the amplitude and phase responses for varying $\bar{k}_{\mathrm{T}}, \bar{m}_{\mathrm{T}}$ and $\bar{b}_{\mathrm{T}}$ are compared to amplitude and phase responses for $k_{\mathrm{T}, 0}, m_{\mathrm{T}, 0}$ and $\bar{b}_{\mathrm{T}, 0}$. For simplification, the amplitude and phase re- sponse of Equation (33) are $\left|\underline{H}_{\mathrm{TMD}}(f)\right|=\left|\underline{H}_{\mathrm{TMD}}\right|$ and $\varphi_{\mathrm{TMD}}(f)=\varphi_{\mathrm{TMD}}$.

\section{Case B1}

Figure $8 \mathrm{a}$ shows the amplitude $\left|\underline{H}_{\mathrm{TMD}}\right|$ and phase $\varphi_{\mathrm{TMD}}$ response for estimated uncertainty $\bar{k}_{\mathrm{T}}=\left[k_{\mathrm{T}}^{-}\right.$; $\left.k_{\mathrm{T}}^{+}\right]=\left[1.18 \mathrm{kN} \cdot \mathrm{m}^{-1} ; 1.44 \mathrm{kN} \cdot \mathrm{m}^{-1}\right]$ compared to $k_{\mathrm{T}, 0}=$ $1.31 \mathrm{kN} \cdot \mathrm{m}^{-1}$ if uncertainty is unknown. According to the first electromechanical analogy [21], the stiffness influences the attenuation system like the inverse of the transducers capacitance. For $k_{\mathrm{T}}^{+}$the tuning frequency of the TMD increases and for $k_{\mathrm{T}}^{-}$the tuning frequency decreases according to: $f_{\mathrm{T}, \mathrm{k}_{\mathrm{T}}^{+}}=1.07 f_{T, 0}$ and $f_{\mathrm{T}, \mathrm{k}_{\mathrm{T}}^{-}}=0.92 f_{T, 0}$. The detuning increases the maximum amplitude and shifts the phase at the $-90^{\circ}$ crossing frequency. For $k_{\mathrm{T}}^{+}$the shift is more distinct.

\section{Case B2}

Figure $8 \mathrm{~b}$ shows the amplitude $\left|\underline{H}_{\mathrm{TMD}}\right|$ and phase $\varphi_{\mathrm{TMD}}$ response for estimated uncertainty $\bar{m}_{\mathrm{T}}=$ $\left[m_{\mathrm{T}}^{-} ; m_{\mathrm{T}}^{+}\right]=[0.0078 \mathrm{~kg} ; 0.0096 \mathrm{~kg}]$ compared to $m_{\mathrm{T}, 0}=$ $0.0087 \mathrm{~kg}$ if uncertainty is unknown. The mass of a TMD effects the attenuated frequency range. With higher masses, the remaining vibration amplitudes decreases. Besides, the mass is affecting the tuning frequency of the TMD according to Equation (34). Hence, $m_{\mathrm{T}}^{+}$will decrease the tuning frequency to $f_{\mathrm{T}, \mathrm{m}_{\mathrm{T}}^{+}}=0.948 f_{T, 0}$ and $m_{\mathrm{T}}^{-}$ increases it to $f_{\mathrm{T}, \mathrm{m}_{\mathrm{T}}^{+}}=1.054 f_{T, 0}$. Regarding the phase 

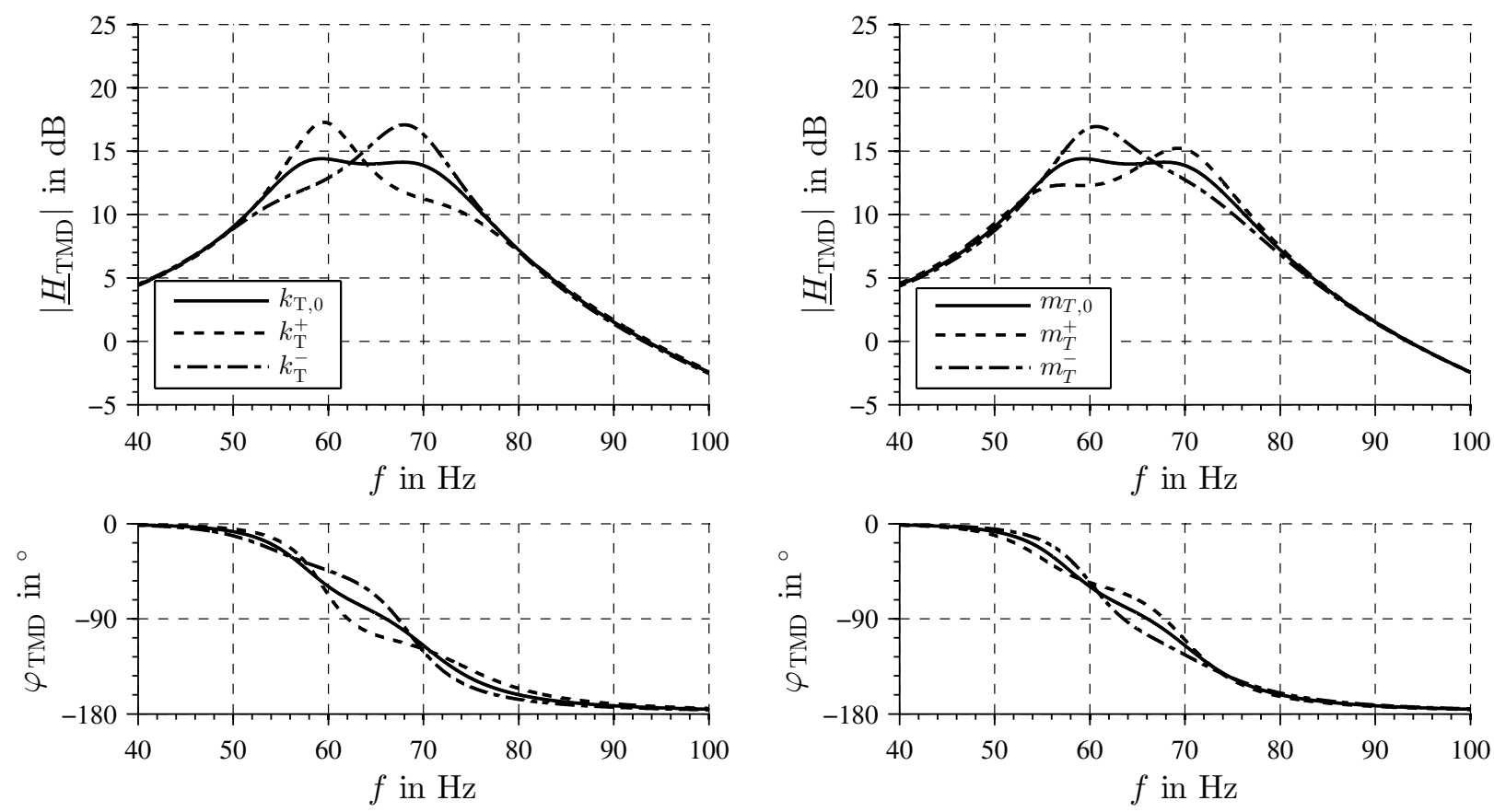

(a)

(b)

Fig. 8. Amplitude and phase response $\left|\underline{H}_{\mathrm{TMD}}\right|$ and $\varphi_{\mathrm{TMD}}$ of the beam with TMD, (a) case B1: $\bar{k}_{\mathrm{T}}=[1.18 \mathrm{kN} / \mathrm{m} ; 1.44 \mathrm{kN} / \mathrm{m}]$ and $k_{\mathrm{T}, 0}=1.31 \mathrm{kN} / \mathrm{m}$, (b) case B2: $\bar{m}_{\mathrm{T}}=[0.0078 \mathrm{~kg} ; 0.0096 \mathrm{~kg}]$ and $m_{\mathrm{T}, 0}=0.0087 \mathrm{~kg}$.

response, $m_{\mathrm{T}}^{-}$and $m_{\mathrm{T}}^{+}$lead to a similar shift of the $-90^{\circ}$ crossing frequency.

\section{Case B3}

Figure 9a shows the amplitude $\left|\underline{H}_{\mathrm{TMD}}\right|$ and phase $\varphi_{\mathrm{TMD}}$ response for estimated uncertainty $\bar{b}_{\mathrm{T}}=$ $\left[b_{\mathrm{T}}^{-} ; b_{\mathrm{T}}^{+}\right]=\left[0.84 \mathrm{Ns}^{-1} ; 1.58 \mathrm{Ns}^{-\mathrm{m}^{-1}}\right]$ compared to

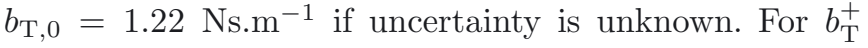
the maximum amplitude increases, while $b_{\mathrm{T}}^{-}$decreases the amplitude only between the two maxima of $\left|\underline{H}_{\mathrm{TMD}}\right|$. Although for $b_{\mathrm{T}}^{-}$the amplitude response is more affected than for $b_{\mathrm{T}}^{+}$, the influence of $b_{\mathrm{T}}^{-}$is less significant, since the maximum amplitude hardly changes, see Figure 9a. In general, $\bar{b}_{\mathrm{T}}$ affects the maximum amplitude in the attenuated frequency range without shifting the tuning frequency significantly. With damping $b_{\mathrm{T}}^{+}$, the phase response approaches the shape of a single resonance. For damping $b_{\mathrm{T}}^{-}$, the phase response shows increasing phase shifts below the tuning frequency and decreasing phase shifts above the tuning frequency.

\section{Case B4}

Figure $9 \mathrm{~b}$ shows the amplitude $\left|\underline{H}_{\mathrm{TMD}}\right|$ and phase $\varphi_{\mathrm{TMD}}$ response for $k_{\mathrm{T}}^{+}, m_{\mathrm{T}}^{-}, b_{\mathrm{T}}^{+}$and $k_{\mathrm{T}}^{-}, m_{\mathrm{T}}^{+}, b_{\mathrm{T}}^{-}$as well as for $k_{\mathrm{T}, 0}, m_{\mathrm{T}, 0}, b_{\mathrm{T}, 0}$. For $k_{\mathrm{T}}^{+}, m_{\mathrm{T}}^{-}, b_{\mathrm{T}}^{+}$the tuning frequency of the TMD change to $f_{\mathrm{T}}^{+}=1.13 f_{\mathrm{T}, 0}$ leading to a maximum peak in the amplitude response below the host structure's eigenfrequency $f_{\mathrm{b}, 1}$. For $k_{\mathrm{T}}^{-}, m_{\mathrm{T}}^{+}$and $b_{\mathrm{T}}^{-}$, the tuning frequency of the TMD is $f_{\mathrm{T}}^{-}=0.88 f_{\mathrm{T}, 0}$ resulting in a comparable peak in the amplitude response, but above the beam's eigenfrequency $f_{1, \mathrm{~b}}$. Regarding the phase response, for $f_{\mathrm{T}}^{-}$the $-90^{\circ}$ crossing frequency increases, whereas for $f_{\mathrm{T}}^{+}$the crossing frequency decreases. The combination $k_{\mathrm{T}}^{-}, m_{\mathrm{T}}^{+}, b_{\mathrm{T}}^{-}$represents the worst case. As for the resonant shunt in case A5, considering only the upper and lower limits of uncertain parameters for determining the worst case is justified.

\subsection{Comparison of maximum amplitudes and amplitudes at $f_{b, 1}$ for resonant shunt and TMD}

Figure 10 shows the maximum absolute amplitude responses $\left|\underline{H}_{\mathrm{sh}}\right|_{\max }$ for the beam with resonant shunt and $\left|\underline{H}_{\mathrm{TMD}}\right|_{\max }$ for TMD according to Figure 5 to 9 for all examined cases A1 to A5 and B1 to B4. $\left|\underline{H}_{\text {sh }}\right|_{\max }$ and $\left|\underline{H}_{\mathrm{TMD}}\right|_{\text {max }}$ are presented for additional masses $m_{\mathrm{p}, 0}$ and $m_{\mathrm{T}, 0}$ varying from $0.0031 \mathrm{~kg}$ to $0.074 \mathrm{~kg}$ or $\mu_{\mathrm{T}}$ and $\mu_{\mathrm{p}}$ varying from 0.025 to 0.6 , respectively. $\mu_{\mathrm{p}}$ and $\mu_{\mathrm{T}}$ are the normalized masses, (see Eq. (34)). All maximum amplitude responses for the beam with resonant shunt and varying $\mu_{\mathrm{p}}$ are shown in light gray. The light gray area is bounded by the maximum amplitude responses $\left|\underline{H}_{\text {sh }}\right|_{\max }$ (solid line) when unknown uncertainty is assumed for $C_{\mathrm{p}, 0}, d_{31,0}, L_{0}, R_{0}$ and the maximum amplitude 

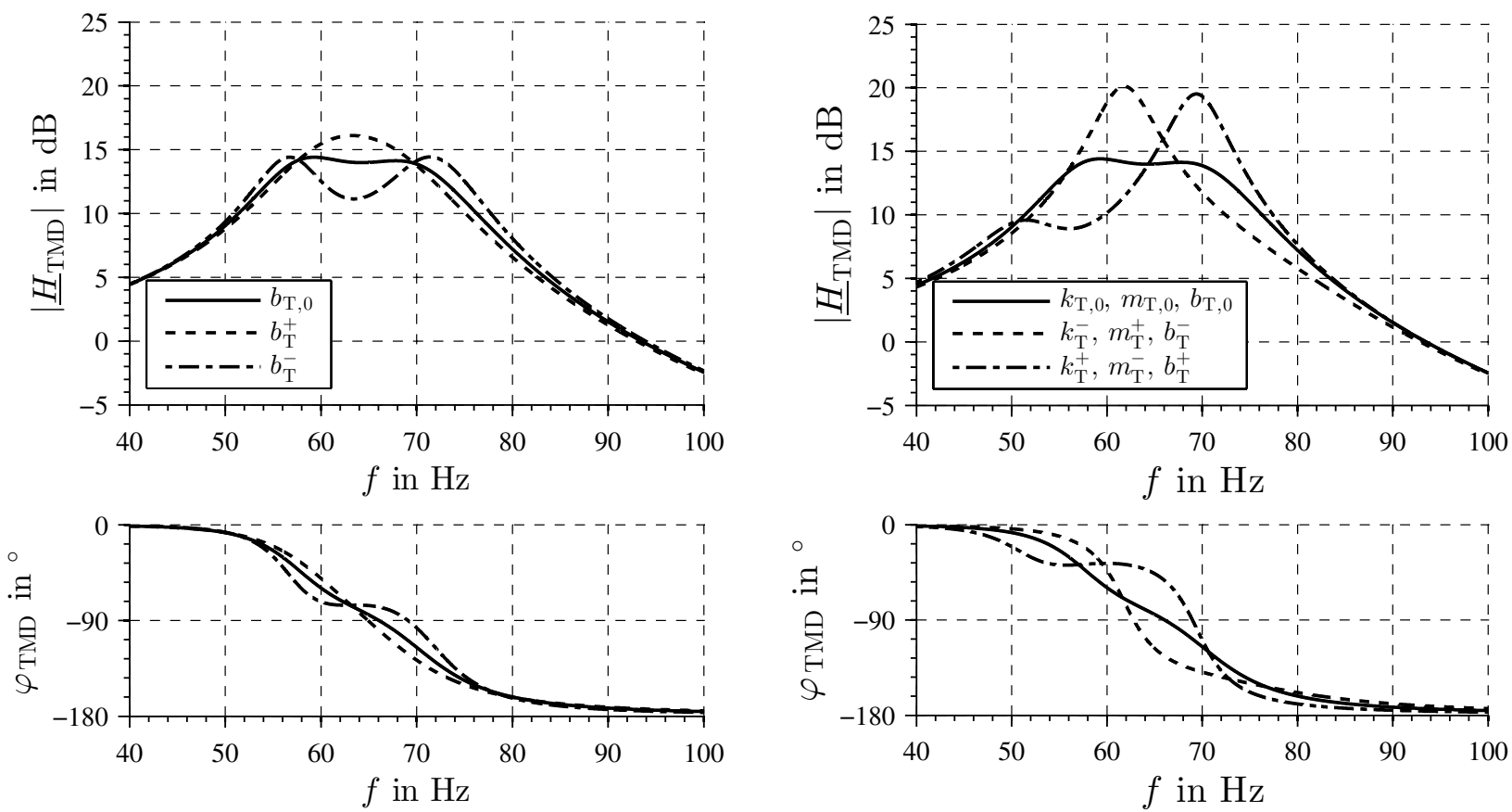

(a)

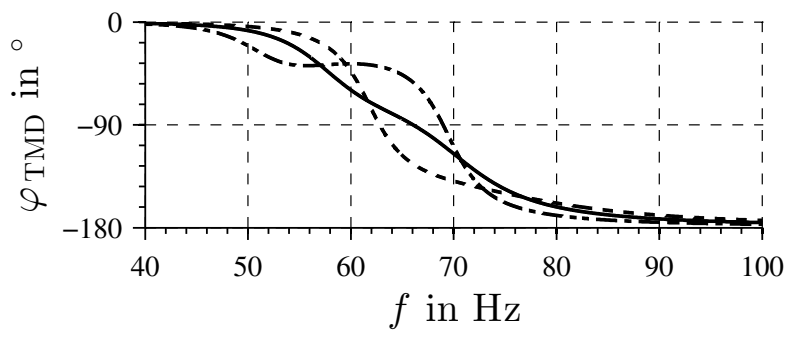

(b)

Fig. 9. Amplitude and phase response $\left|\underline{H}_{\mathrm{TMD}}\right|$ and $\varphi_{\mathrm{TMD}}$ of the beam with TMD, (a) case B3: $\bar{b}_{\mathrm{T}}=[0.84 \mathrm{Ns} / \mathrm{m}, ; 1.58 \mathrm{Ns} / \mathrm{m}]$ and $b_{\mathrm{T}, 0}=1.22 \mathrm{Ns} / \mathrm{m}$, (b) case B4 and $k_{\mathrm{T}, 0}, m_{\mathrm{T}, 0}, b_{\mathrm{T}, 0}$.

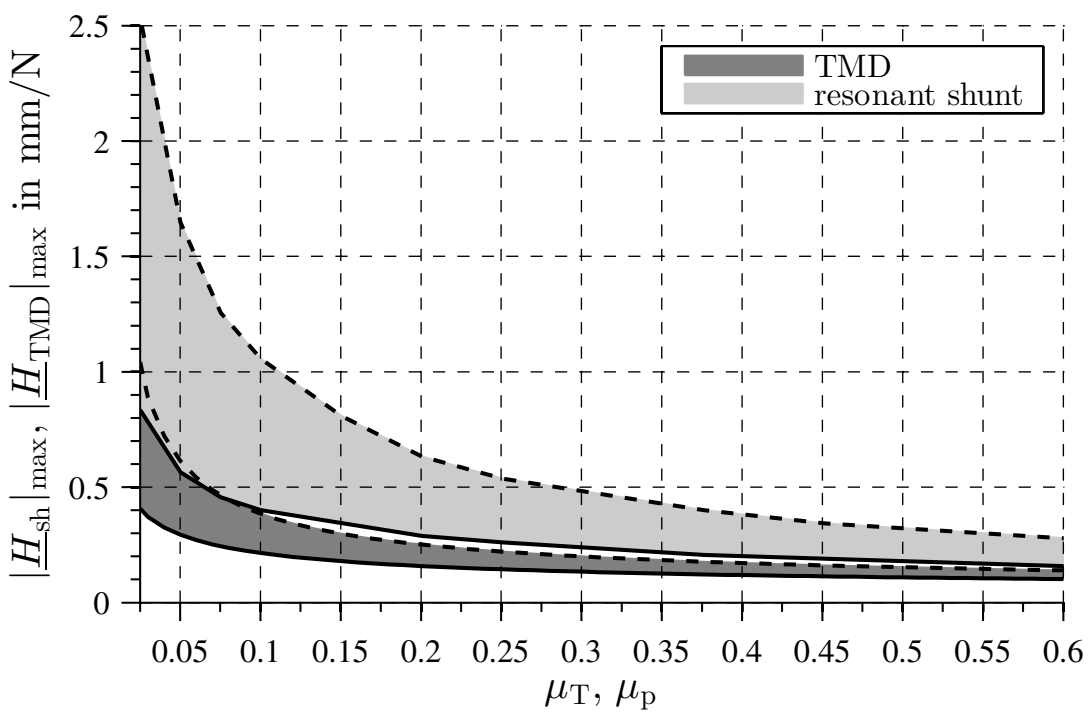

Fig. 10. Maximum amplitude responses of beam with resonant shunt $\left|\underline{H}_{\mathrm{sh}}\right| \max$ and TMD $\left|\underline{H}_{\mathrm{TMD}}\right| \max$ due to unknown uncertainty (solid lines), maximum amplitude responses of beam with resonant shunt $\left|\underline{H}_{\text {sh }}\right|$ max and TMD $\left|\underline{H}_{\mathrm{TMD}}\right|_{\text {max }}$ due to estimated uncertainty case $\mathrm{A} 5\left(C_{\mathrm{p}}^{+}, d_{31}^{-}, L^{+}, R^{+}\right)$and case $\mathrm{B} 4\left(k_{\mathrm{T}}^{-}, m_{\mathrm{T}}^{+}, b_{\mathrm{T}}^{-}\right)$(dashed lines) 


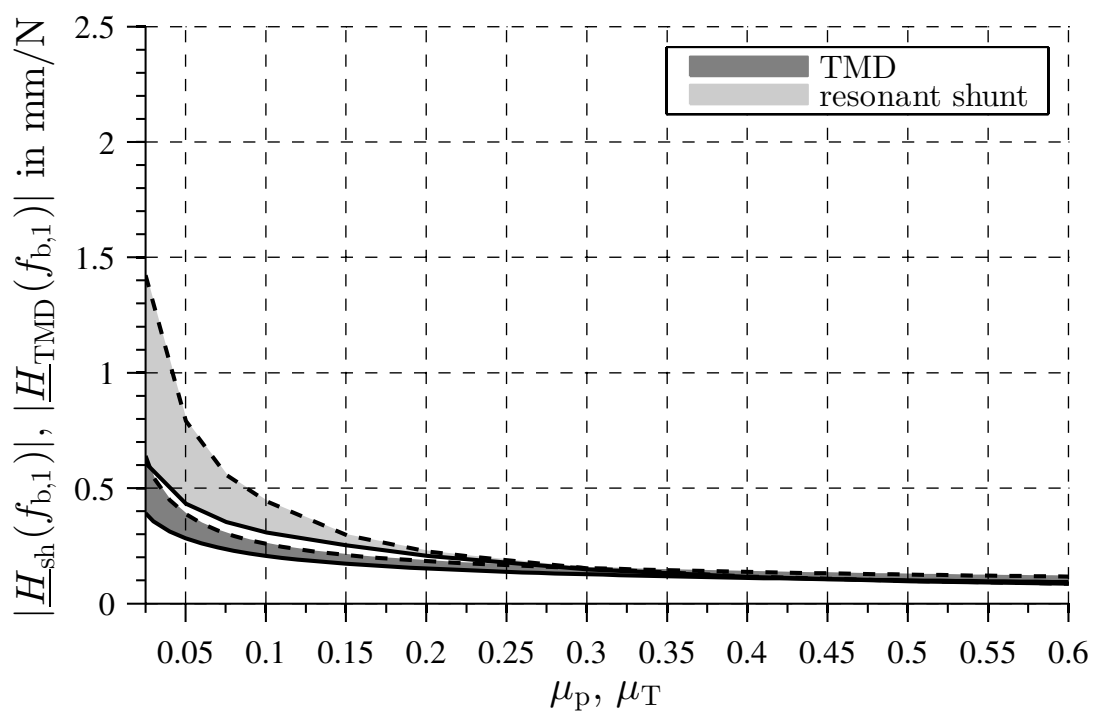

Fig. 11. Amplitude responses of beam with resonant shunt $\left|\underline{H}_{\mathrm{sh}}\left(f_{\mathrm{b}, 1}\right)\right|$ and TMD $\left|\underline{H}_{\mathrm{TMD}}\left(f_{\mathrm{b}, 1}\right)\right|$ due to unknown uncertainty (solid lines) unacknowledged uncertainty, amplitude responses of beam with resonant shunt $\left|\underline{H}_{\mathrm{sh}}\left(f_{\mathrm{b}, 1}\right)\right|$ and TMD $\left|\underline{H}_{\mathrm{TMD}}\left(f_{\mathrm{b}, 1}\right)\right|$ due to estimated uncertainty case $\mathrm{A} 5\left(C_{\mathrm{p}}^{-}, d_{31}^{-}, L^{-}, R^{+}\right)$and case $\mathrm{B} 4\left(k_{\mathrm{T}}^{-}, m_{\mathrm{T}}^{+}, b_{\mathrm{T}}^{-}\right)$(dashed lines).

responses $\left|\underline{H}_{\text {sh }}\right| \max$ (dashed line), for the worst case A5 with $C_{\mathrm{p}}^{+}, d_{31}^{-}, L^{+}, R^{+}$. All maximum amplitude responses for the beam with TMD and varying $\mu_{\mathrm{T}}$ are shown in dark gray. The dark gray area is bounded by the maximum amplitude responses $\left|\underline{H}_{\mathrm{TMD}}\right|_{\max }$ (solid line) when unknown uncertainty is assumed for $k_{\mathrm{T}, 0}, m_{\mathrm{T}, 0}$ and $b_{\mathrm{T}, 0}$ and the maximum amplitude responses $\left|\underline{H}_{\mathrm{TMD}}\right|_{\max }$ (dashed line), for worst case $\mathrm{B} 4$ with $k_{\mathrm{T}}^{-}, m_{\mathrm{T}}^{+}, b_{\mathrm{T}}^{-}$.

Both approaches, resonant shunt and TMD, show asymptotic decreasing amplitudes with increasing additional masses. The electromechanical coupling coefficient $K_{31}$ (see Eq. (24)), and, thus, the maximum amplitude response $\left|\underline{H}_{\mathrm{sh}}\right| \max$ will change for different $l_{\mathrm{p}}$ and $h_{\mathrm{p}}$ and different mass ratios $\mu_{\mathrm{p}}$ of piezoelectric transducers, respectively. For each thickness $h_{\mathrm{p}}$ one length $l_{\mathrm{p}}$ exists with the coupling coefficient $K_{31}$ to be maximal and $\left|\underline{H}_{\text {sh }}\right| \max$ to be minimal that is shown only in Figure 10.

Resonant shunt and TMD (solid lines) achieve maximum amplitudes less than $20 \%$ of the beam's maximum amplitude. However, the TMD achieves a higher vibration attenuation than the resonant shunt with the same additional masses. Usually $[22], \mu_{\mathrm{T}}$ is recommended to be less than $20 \%$. For $\mu_{\mathrm{T}} \leq 0.2$, the maximum amplitudes $\left|\underline{H}_{\mathrm{TMD}}\right| \max$ are significantly smaller than the maximum amplitudes $\left|\underline{H}_{\text {sh }}\right|_{\text {max }}$. The maximum deviation of the resonant shunt is $2.5 / 0.83\left|\underline{H}_{\mathrm{sh}}\right|_{\max } \approx 3\left|\underline{H}_{\mathrm{sh}}\right|_{\max }$ at $\mu_{\mathrm{p}}=0.025$ and $0.26 / 0.16\left|\underline{H}_{\mathrm{sh}}\right|_{\max } \approx 1.6\left|\underline{H}_{\mathrm{sh}}\right|_{\max }$ at $\mu_{\mathrm{p}}=0.6$ in case of unknown uncertainty. For the TMD it is $1.2 / 0.4\left|\underline{H}_{\mathrm{TMD}}\right|_{\max }=3\left|\underline{H}_{\mathrm{TMD}}\right|_{\max }$ at $\mu_{\mathrm{T}}=0.025$ and $0.14 / 0.1\left|\underline{H}_{\mathrm{TMD}}\right|_{\max }=1.4\left|\underline{H}_{\mathrm{TMD}}\right|_{\max }$ at $\mu_{\mathrm{T}}=0.6$ in case of unknown uncertainty. The absolute deviations are smaller for the TMD but the relative deviations are comparable. However, vibration attenuation with TMD is less sensitive to the assumed estimated uncertainty. With increasing additional masses, i.e. the attenuation capability of resonant shunt and TMD increase, the uncertainty for both approaches decrease. With higher $\mu_{\mathrm{p}}$ and $\mu_{\mathrm{T}}$ the broad band attenuation increases and, thus, both systems get less sensitive to deviating tuning frequencies.

Figure 11 shows the amplitude responses $\left|\underline{H}_{\mathrm{sh}}\left(f_{\mathrm{b}, 1}\right)\right|$ for resonantly shunted transducers and $\left|\underline{H}_{\mathrm{TMD}}\left(f_{\mathrm{b}, 1}\right)\right|$ for the TMD at the beam's first eigenfrequency $f_{\mathrm{b}, 1}$. Dashed lines show cases $\mathrm{A} 5$ with $C_{\mathrm{p}}^{-}, d_{31}^{-}, L^{-}, R^{+}$and cases B4 with $k_{\mathrm{T}}^{-}, m_{\mathrm{T}}^{+}, b_{\mathrm{T}}^{-}$. Compared to Figure 10, the amplitude attenuation (solid line) for the TMD does hardly change, whereas the amplitude attenuation for the resonant shunt (solid line) increases. This is due to the tuning method presented in Section 2.2, which does not lead to complete equalized amplitudes in the attenuated frequency range. Since the structure's stiffness and mass change with attached piezoelectric transducers the mechanical eigenfrequency $f_{\mathrm{SC}, 1}$ increases (see Eq. (25)). Thus, the attenuated frequency range will also shift leading to an additional amplitude attenuation. The maximum deviation of the resonant shunt is $1.41 / 0.62\left|\underline{H}_{\text {sh }}\right|_{\max } \approx 2.3\left|\underline{H}_{\text {sh }}\right|_{\max }$ at $\mu_{\mathrm{p}}=0.025$ in case of unknown uncertainty. For the TMD $0.62 / 0.39\left|\underline{H}_{\mathrm{TMD}}\right|_{\max } \approx 1.6\left|\underline{H}_{\mathrm{TMD}}\right|_{\max }$ at $\mu_{\mathrm{T}}=$ 0.025 in case of unknown uncertainty. $\left|\underline{H}_{\mathrm{sh}}\left(f_{\mathrm{b}, 1}\right)\right|$ and $\left|\underline{H}_{\mathrm{TMD}}\left(f_{\mathrm{b}, 1}\right)\right|$ are similar from $\mu_{\mathrm{T}}=\mu_{\mathrm{p}}=0.3$. This is still above the recommended maximum $\mu_{\mathrm{T}}=0.2$. Furthermore, the deviations in $\left|\underline{H}_{\mathrm{sh}}\left(f_{\mathrm{b}, 1}\right)\right|$ and $\left|\underline{H}_{\mathrm{TMD}}\left(f_{\mathrm{b}, 1}\right)\right|$ due to estimated uncertainty are smaller compared to the ones from Figure 10. As observed in Figures 7 and 9b, the maximum amplitude responses occur right and left of the tuning frequency, thus, the amplitude responses at $f_{\mathrm{b}, 1}$ are less effected by a detuned attenuation systems. This effect is more distinctive for the resonant shunt since it is supported by the shift of $f_{\mathrm{SC}, 1}$ and $\left|\underline{H}_{\mathrm{sh}}\left(f_{\mathrm{b}, 1}\right)\right|$ gets less influenced by uncertain parameters. 


\section{Conclusion}

The effect of parametric estimated uncertainty on vibration attenuation of a beam clamped at both ends with (a) resonantly shunted piezoelectric transducer and (b) tunes mass damper TMD is investigated separately. It is shown, that both approaches, resonant shunt and TMD, achieve remaining amplitudes less than $20 \%$ of the beam's amplitude. A TMD achieves higher vibration attenuation than a resonant shunt with the same mass that has to be attached additionally on the beam, either as mass of piezoelectric material for shunt damping or as seismic mass for the TMD. Furthermore, vibration attenuation using TMD is less sensitive to the assumed estimated uncertainty. With increasing additional masses and, hence, increasing attenuation performance, both systems get less sensitive to detuning due to uncertainty. Comparing the amplitudes at the first beam eigenfrequency, uncertainty decreases. Attaching piezoelectric transducers to the beam, increases the resonance frequency. This leads to further reduction of the amplitude response of the resonant shunt at the beam's eigenfrequency and the amplitude at the beam's first eigenfrequency gets less affected by estimated uncertainty. Further examinations will investigate resonant shunt damping with negative capacitance regarding parametric uncertainty and additional masses.

Acknowledgements. The authors like to thank the German Research Foundation DFG for funding this research within the SFB 805.

\section{References}

[1] S.O.R. Moheimani, A.J. Fleming, Piezoelectric transducers for vibration control and damping, Springer, Verlag, 2006

[2] S. Alessandroni, U. Andreaus, F. dell'Isola, M. Porfiri, A passive electric controller for multimodal vibrations of thin plates, Comput. Struct. 83 (2005) 1236-1250

[3] M. Neubauer, J. Wallaschek, Vibration damping with shunted piezoceramics: Fundamentals and technical applications, Mech. Syst. Signal Process. 36 (2013) 36-52

[4] F. Casadei, M. Ruzzene, L. Dozio, K.A. Cunefare, Broadband vibration control through periodic arrays of resonant shunts: experimental investigation on plates, Smart Mater. Struct. 19 (2009) 015002

[5] U. Andreaus, F. dell'Isola, M. Porfiri, Piezoelectric passive distributed controllers for beam flexural vibrations, Int. J. Vib. Control 23 (2004) 625-659

[6] U. Andreaus, M. Porfiri, Effect of electrical uncertainties on resonant piezoelectric shunting, J. Intell. Mater. Syst. Struct. 18 (2007) 477-485
[7] H.F.L dos Santos, M.A. Trindade, Structural vibration control using extension and shear active-passive piezoelectric networks including sensitivity to electrical uncertainties, J. Braz. Soc. Mech. Sci. Eng. 33 (2011) 287-301

[8] B. Götz, Comparison of mechanical and electromechanical vibration absorbers in consideration of the additional mass, Master's thesis, Technische Universität Darmstadt, 2013

[9] N.W. Hagood, W.H. Chung, A. von Flotow, Modelling of piezoelectric actuator dynamics for active structural control, J. Intell. Mater. Syst. Struct. 1 (1990) 327-354

[10] P. Hagedorn, A. DasGupta, Vibrations and waves in continuous mechanical systems, John Wiley \& Sons, 2007

[11] U. Andreaus, P. Baragatti, L. Placidi, Experimental and numerical investigations of the responses of a cantilever beam possibly contacting a deformable and dissipative obstacle under harmonic excitation, Int. J. Non-Linear Mech. (2015) (in press)

[12] M. Neubauer, R. Oleskiewicz, K. Popp, T. Krzyzynski, Optimization of damping and absorbing performance of shunted piezo elements utilizing negative capacitance, J. Sound Vib. 298 (2006) 84-107

[13] L.P. Huelsman, Active and Passive Analog Filter Design, McGraw-Hill, 1993

[14] S. Krenk, J. Høgsberg, Tuned mass absorbers on a flexible structure, J. Sound Vib. 333 (2013) 1577-1595

[15] H. Hanselka, R. Platz, Ansätze und Maßnahmen zur Berrschung von Unsicherheit in lasstragenden Systemen des Maschinenbaus (engl. Controlling uncertainties in load carrying systems), Konstruktion 11/12 (2010) 5562

[16] T. Eifler, G.C. Enss, M. Haydn, L. Mosch, R. Platz, H. Hanselka, Approach for a consistent description of uncertainty in process chains of load carrying mechanical structures, J. Appl. Mech. Mater. 104 ( 2012) 133-144

[17] R. Platz, S. Ondoua, G.C. Enss, T. Melz, Approach to evaluate uncertainty in passive and active vibration reduction, Proceedings of the 32nd IMAC, A Conference and Exposition on Structural Dynamics, 2014, pp. 345352

[18] VDI 2962, Vibration Insulation-Insulation elements, Part 2, Verein Deutscher Ingenieure, Beuth Verlag Berlin, 2007

[19] S.J. Rupitsch, J. Ilg, R. Lerch, Enhancement of the inverse method enabling the material parameter identification for piezoceramics, IEEE International Ultrasonics Symposium Proceedings, 2011, pp. 357-360

[20] GUM, GUM - Guide to the expression of uncertainty in measurement, Joint Committee for Guides in Metrology, 2008

[21] S. Priya , D.J. Inman, Energy Harvesting Technologies, Springer, Verlag, 2009

[22] VDI 3833, Dynamic vibration absorber and dynamic vibration absorption, Part 2, Verein Deutscher Ingenieure, Beuth Verlag, Berlin, 2006 